\title{
Pakisaurus balochistani (Poripuchia, Slender Titanosauria, Sauropoda) Associated Skeletons Found from the Latest Maastrichtian Vitakri Formation of Pakistan and Referred Fossils from India; Filling of Important Missing Links of Isisaurus colberti Titanosaur Found from Pakistan
}

\author{
Muhammad Sadiq Malkani \\ Geological Survey of Pakistan, Muzaffarabad, Pakistan \\ Email: malkanims@yahoo.com
}

How to cite this paper: Malkani, M.S (2020) Pakisaurus balochistani (Poripuchia, Slender Titanosauria, Sauropoda) Associated Skeletons Found from the Latest Maastrichtian Vitakri Formation of Pakistan and Referred Fossils from India; Filling of Important Missing Links of Isisaurus colberti Titanosaur Found from Pakistan. Open Journal of Geology, 10, 408-447. https://doi.org/10.4236/ojg.2020.104019

Received: March 10, 2020

Accepted: April 14, 2020

Published: April 17, 2020

Copyright $\odot 2020$ by author(s) and Scientific Research Publishing Inc. This work is licensed under the Creative Commons Attribution International License (CC BY 4.0).

\begin{abstract}
Recently two slender and medium to large sized titanosaur taxa like Pakisaurus balochistani and Isisaurus colberti of pakisaurids Poripuch along with small sized stocky Saraikimasoom and medium sized stocky Gspsaurus of gspsaurids Poripuch have been recognized from Indo-Pakistan subcontinent. The diagnosis and description of Pakisaurus balochistani and some missing elements of Isisaurus colberti discovered from Pakistan are added here for understanding of possible fuller anatomy of slender titanosaurs. Further so far no any research information regarding the comparison of titanosaurs of India and Pakistan is available. Here present research provides the comparison between titanosaurs recognized from Pakistan and India.
\end{abstract}

\section{Keywords}

Titanosauria, Slender Poripuchia, Pakisaurus balochistani, Isisaurus colberti, Comparison, Latest Cretaceous, Indo-Pakistan Subcontinent http://creativecommons.org/licenses/by/4.0/

\section{(c) (i) Open Access}

\section{Introduction}

Mesozoic vertebrates are known from India more than one and half century ago [1]. But from Pakistan the first bone of titanosaurian sauropod dinosaur [2] re- 
cently was discovered in 2000. So far 3000 fossil bones and pieces were discovered from Pakistan. All the fossil bones of titanosaurs were reported from the latest Cretaceous (67 - 66 Ma) Vitakri Formation from Pakistan [3] [4] and its coeval Lameta sediments from India. The skull of Marisaurus jeffi titanosaur [5], different types of osteoderms of titanosaurs were reported first time in Asia [6] and titanosauriforms or basal titanosaur [7] were reported from Pakistan. Five taxa of titanosaurs from Pakistan namely Pakisaurus balochistani, Sulaimanisaurus gingerichi and Khetranisaurus barkhani of pakisaurids, Marisaurus jeffi and Balochisaurus malkani of balochisaurids were established on diverse caudal vertebrae [8]. This extended abstract [8] was submitted earlier than papers [5] [6] [7] but due to conference date changing from 2003 to 2004, the papers [5] [6] [7] were published earlier than conference [8] paper. These taxa of titanosaurs were described and figured in 2006 [9]. Diverse presacral vertebrae of titanosaurs were also reported from Pakistan [10]. Later on many postcranial fossils were referred to Marisaurus jeffi [11] [12] [13], Balochisaurus malkani [13] [14] and Pakisaurus balochistani [15]. These titanosaurs were considered invalid [16] except Isisaurus and Jainosaurus. The fossils from Pakistan were diagnostic and consequently Gspsaurus pakistani [17] and Saraikimasoom vitakri [17] were established on diagnostic skull and snout which were previously referred to Marisaurus jeffi [9] and Balochisaurus malkani [9] respectively. Further Nicksaurus razashahi [17] [18] and Maojandino alami [18] [19] were established on holotypic cranial, vertebral and appendicular elements which were previously referred to Marisaurus jeffi [9] and Balochisaurus malkani [9] respectively. Recently four titanosaurs from Indo-Pakistan like Gspsaurus pakistani [20] [21], Saraikimasoom vitakri [22] [23], Pakisaurus balochistani [24] and here, and Isisaurus colberti [25] (and here) were diagnosed out of total 15 named taxa from Indo-Pakistan subcontinent.

There were suggestions from Prof. Ashok Sahni and Dr. Okmar Verma from India and Dr. Nick Longrich from UK to carry out dry and wet sieving of sediments at 7, 18, 25 mesh to carry out microvertebrates study for comparisons with Indian microvertebrates but it is not possible due to security problem. The author collected about 2 kilograms of stream sediments (about coarse sandy size) from Bara Khadro section of Lakhi Range, Sind and after study of a few 100 gram, one silicified tooth was found [26]. It tells incouraging results to continue further microvertebrates study especially in Vitakri dome and surrounding area of Sulaiman foldbelt (Balochistan Province of Pakistan) and Bara-Khadro and other anticlinal core areas of Lakhi thrusted anticline of eastern Kirthar foldbelt (Sindh Province of Pakistan).

So far Mesozoic vertebrates are found from about 30 localities. Some localities have many sites. Some major localities belong to Vitakri dome, Dhaola-Andhari, Andhari-Chapar (Sadiqani-Chapar), Mari Bohri and Rakhni (Mat Khetran-Kachar) areas of Barkhan District of Balochistan, Beaker area of Dera Bugti District of Balochistan, and Fort Munro-Rakhi Gaj areas of Dera Ghazi Khan District of 
South Punjab [14]. Vitakri dome includes the Sangiali 1, Bor 2, Shalghara 3, Kinwa 4, mid Kinwa 4m, north Kinwa 4n, Top Kinwa 16, Alam 19 (19c), north Alam 19n, south Alam 19s, Eastern Alam 18, Dada Pahi 17 and Roosmani 20. The Dhaola-Gambrak area included Dagar 5, Goes Wanga Pass 6, Zubra peak 7, South Zubra or Basti Nala 7, Darwaza 8, Grut 9, Rahi Wali 10, northeast 11, eastnortheast Dolwahi 12 and Dolwahi east 13. Andhari-Chapar range produced only one locality namely Sadiqani Chapar locality 14 which was visited; the remaining areas of this range is not visited so far. Mari Bohri area produced also only one Mari Bohri 15 locality with 4 or 5 sites. Fort Munro area has produced Top Girdu 24 and Mian Ghundi 25 (Khar Fort Munro). Rakhni area produced Mat Khetran 21 and Kachar 23. Beakar (Baekar/Beaker) area of Dera Bugti District produced one locality namely Bhal 22 [14]. At the end locality numbers are marked. The other significant areas are Chitri and Dragal Maarri of Rajan Pur district, South Punjab especially for bones, eggs and footprints. Most of these localities belong to Sulaiman (middle Indus) Range and their locations are shown in maps [14]. However some localities from western Kirthar range, Khuzdar district of Balochistan [14] and Khadro-Bara and other anticlinal core areas of Laki thrusted anticline of eastern Kirthar range, Jam Shoro District of Sindh [26]. Footprints and trackways of late Jurassic dinosaurs were also found from $\mathrm{Ma}$ lakhel area of Mianwali district, Kohat-Potwar basin, Punjab [27].

Here two slender titanosaurs from Indo-Pakistan namely Pakisaurus balochistani and Isisaurus colberti are recognized. Previously no any comparisons of slender titanosaurs from Pakistan and India are available, so here the Pakisaurus balochistani the slender titanosaur are being described and compared with other titanosaurs from India and Pakistan. Further the missing gaps especially femur, tibia, fibula and metatarsal of hind limb of Isisaurus colberti are discovered from Pakistan and being added here.

\section{Pakisaurus balochistani}

The systematic paleontology of Pakisaurus balochistani is as follows.

Dinosauria [28];

Saurischia [29];

Sauropoda [30];

Titanosauria [31];

Poripuchia [4] [27];

Pakisauridae [9];

Pakisaurus [9];

Pakisaurus balochistani [9];

(Figures 1-5).

The holotypic postcranial materials (Figures 1-3) of Pakisaurus balochistani were found from South Kinwa 4, Pakistan Dinosaur Locality 4/PDL 4 . These holotypic materials (Figures 1-3) were considered associated and belong to one animal due to finding from same locality and same formation, fit in size and no 


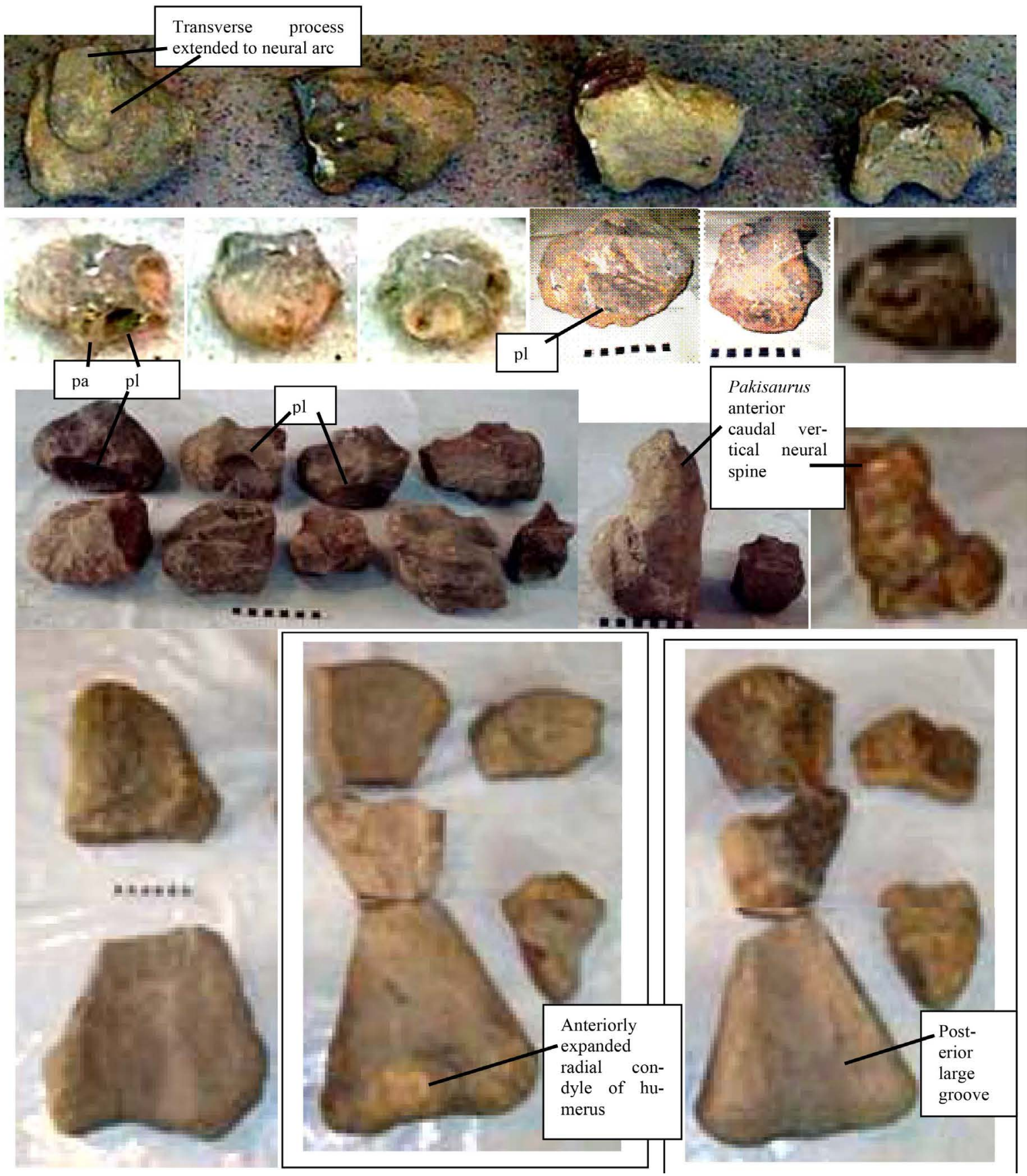

Figure 1. Pakisaurus balochistani holotypic remains from south Kinwa 4 (continued in Figure 2 and Figure 3). Row 1, four caudal vertebrae MSM-11-4, MSM-12-4, MSM-13-4, MSM-14-4; for scale pl. See [9]. Row 2, cervicodorsal vertebrae MSM-133-4 lateral, anterior and posterior views; presacral vertebra MSM-1011-4 in lateral and anterior views; sacral pair MSM-1008-4. Row 3, photo 1/p1, subrow 1, presacral vertebrae MSM-340-4, MSM-809-4, MSM-1011-4, MSM-517-4; subrow 2, presacral vertebrae MSM-810-4, MSM-342-4, MSM-800-4, MSM-341-4, MSM-376-4; p2, anterior and mid caudal vertebrae MSM-207-4 and MSM-763-4; p3, mid caudal vertebra MSM-1010-4 for scale see (Figure 5). Row 4, p1, a right femur (proximal femur MSM-595-4, distal right MSM-200-4); p2, 3, column 1, proximal right humerus MSM-202-4, mid humerus MSM-268-4, distal humerus MSM-193-4; column 2, mid humeri MSM-210-4, MSM-210a-4, for scale see (Figure 3). Scale, each black or white digit is $1 \mathrm{~cm}$. Full specimen number is like GSP/MSM-11-4 where GSP is the abbreviation of Geological Survey of Pakistan, MSM is the abbreviation of collector M. Sadiq Malkani, 11 is the serial number and last number 1 is the locality number. Localities number and location can be seen in [14]. 


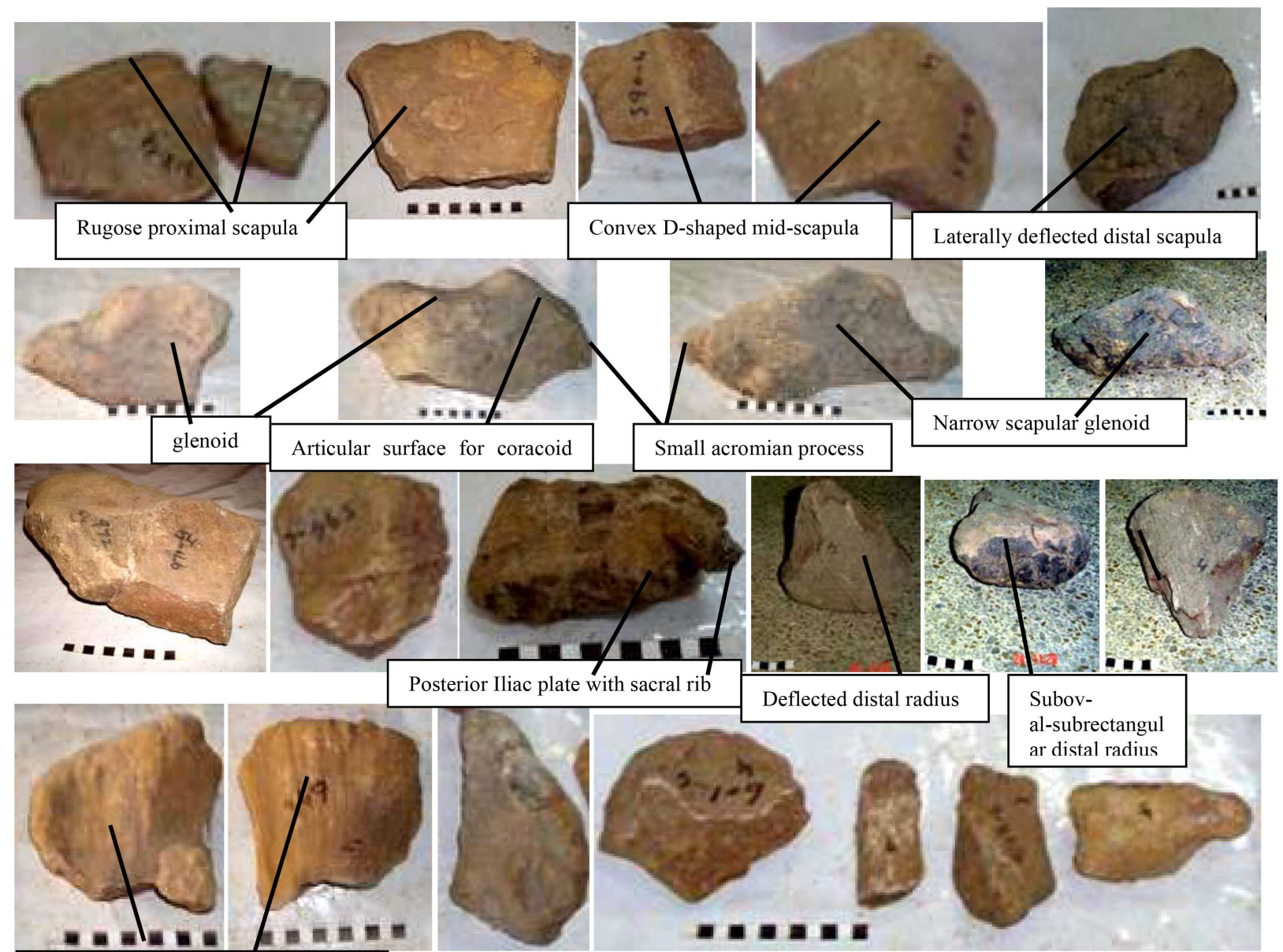

Parallel fibrous structures of fibula
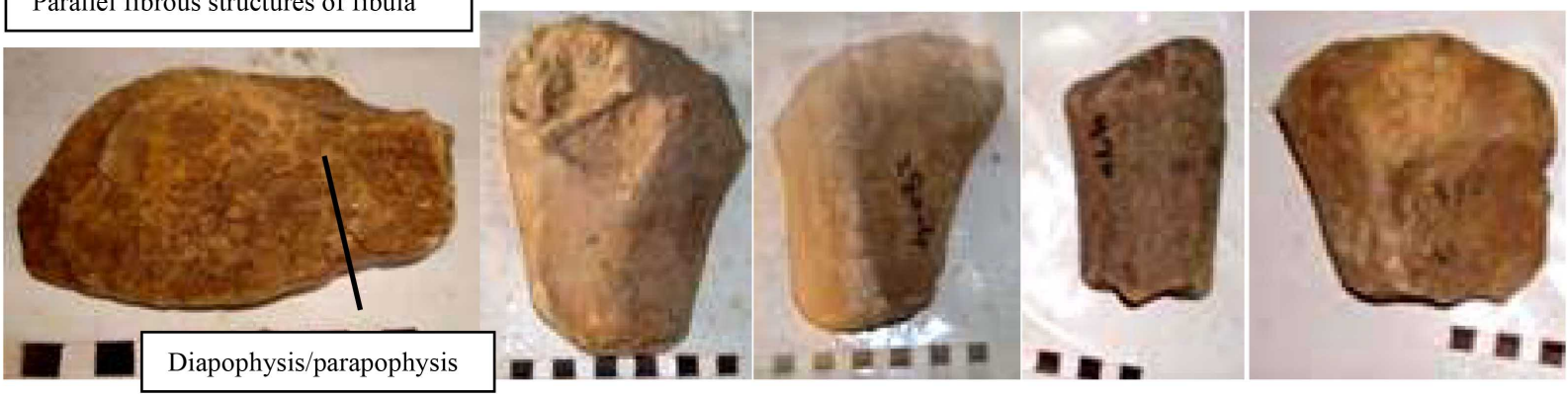

Figure 2. Pakisaurus balochistani holotypic remains from south Kinwa 4 (continued from Figure 1). Row 1, photo 1/p1, proximal scapula in two pieces MSM-318-4, MSM-319-4 for scale see [15]; p2, proximal scapula MSM-201-4; p3, mid scapula MSM-590-4 for scale see [15]; p4, mid scapula sections MSM-593-4 for scale see [15]; p5, left mid scapula MSM-203-4. Row 2, p1, right distal scapula with glenoid surface MSM-205-4; p2, 3, 4 left distal scapula with glenoid surface MSM-162-4 in 3 views. Row 3, p1, proximal anterior process of ilium MSM-971-4 and MSM-972-4 two piece; p2, part of Ilium MSM-594-4 for scale see [15]; p3, posterior part of ilium with rod type rib process MSM-806-4; p4, 5, 6, distal radius MSM-159-4 in 3 views. Row 4, p1, 2, proximal right fibula MSM-349-4 in two views, p3, distal fibula MSM-580-4; p4, neural spine MSM-601-4, neural arches parts MSM-804-4 and un-numbered. Row 5, p1, diapophysis/prezygapophysis MSM-878-4; p2, 3, partial metacarpal MSM-280-4 in two views; p4, partial metacarpal MSM-970-4; p5, partial metatarsal MSM-350-4. Scale, each black or white digit is $1 \mathrm{~cm}$. Note, at places the locality name with locality number are mentioned as like south Kinwa 4, here south Kinwa is the locality name and 4 is the locality number.

duplication. The holotypic skeletal bones (Figures 1-3) are consistent with other associations of bones of this taxon and other 3 recognized taxa from Pakistan 

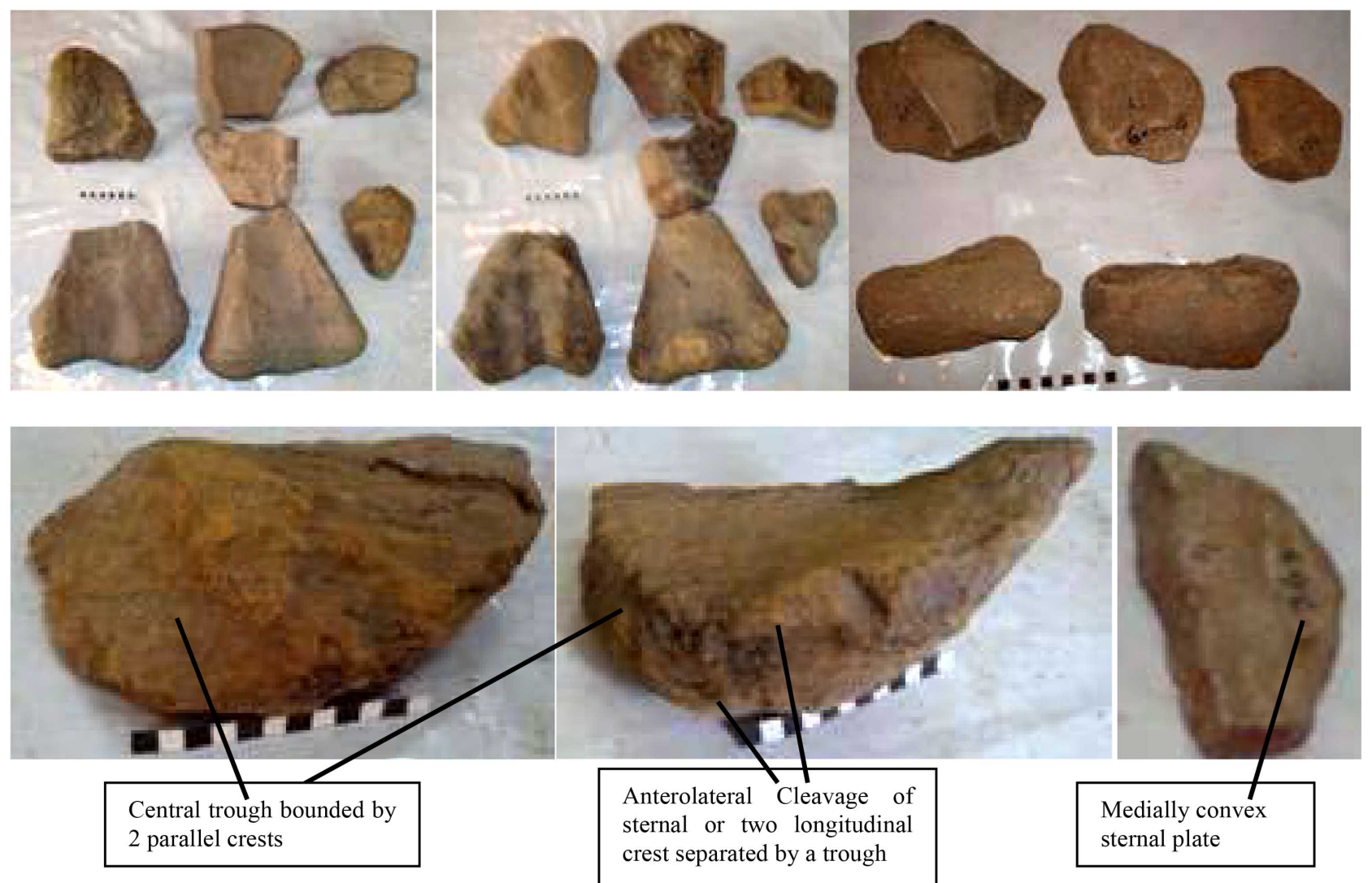

Figure 3. Pakisaurus balochistani holotypic remains from south Kinwa 4 (continued from Figure 1 and Figure 2). Row 1, p1, 2, column 1, proximal and distal right femur MSM-595-4, MSM-200-4; column 2, proximal humerus MSM-202-4, mid humerus MSM-268-4, distal humerus MSM-193-4 (reverse view than proximal); column 3, mid humeri MSM-210-4, MSM-210a-4; p3, subrow 1, a pair of proximal ulnae-left and right proximal ulnae MSM-603-4, MSM-600-4, proximal left fibula MSM-384-4; subrow 2, one ray of proximal ulna MSM-211-4, distal scapula MSM-678-4. Row 2, p1, 2, anterolateral sternal MSM-355-4 in two views; p3, sternal medial convex MSM-598-4. Scale, each black or white digit is $1 \mathrm{~cm}$. GSP-Geological Survey of Pakistan. MSM-Muhammad Sadiq Malkani. The formal specimen numbers are like GSP/MSM-200-4 but briefly represented by MSM-200-4 in literature. The central number 200 represents the serial number and last number 4 represents locality number of Kinwa or south Kinwa.

and India. A postcranial skeleton from lower Bor (Figure 4) is significant exemplar of Pakisaurus balochistani. Some materials referred from northwestern Top Kinwa 16 (Figure 5), Shalghara 3 (Figure 5), North Alam 19n (Figure 5), and east Dolwahi 13 (Figure 5) localities from Pakistan. A braincase (Figure 5) and some other fossils were also referred from India.

The lower Bor skeleton (Figure 4) is represented by a pair of humerus (left and right humerus), a pair of femur (left and right femur), a pair of tibia (left and right tibia), a fibula and possibly a caudal vertebra. Most of these bones are partial and incomplete but represents typical and key features of a taxon Pakisaurus balochistani. The association of bones are evidenced by the field occurrence at one place/site/locality within a diameter of 10 meter on the just close to western side of peak, on the surface of host upper shale unit, fit in size, pair of bones with same size and features, and no duplication of bones representing another animal. Here the bones were found from the upper shale unit of Vitakri 


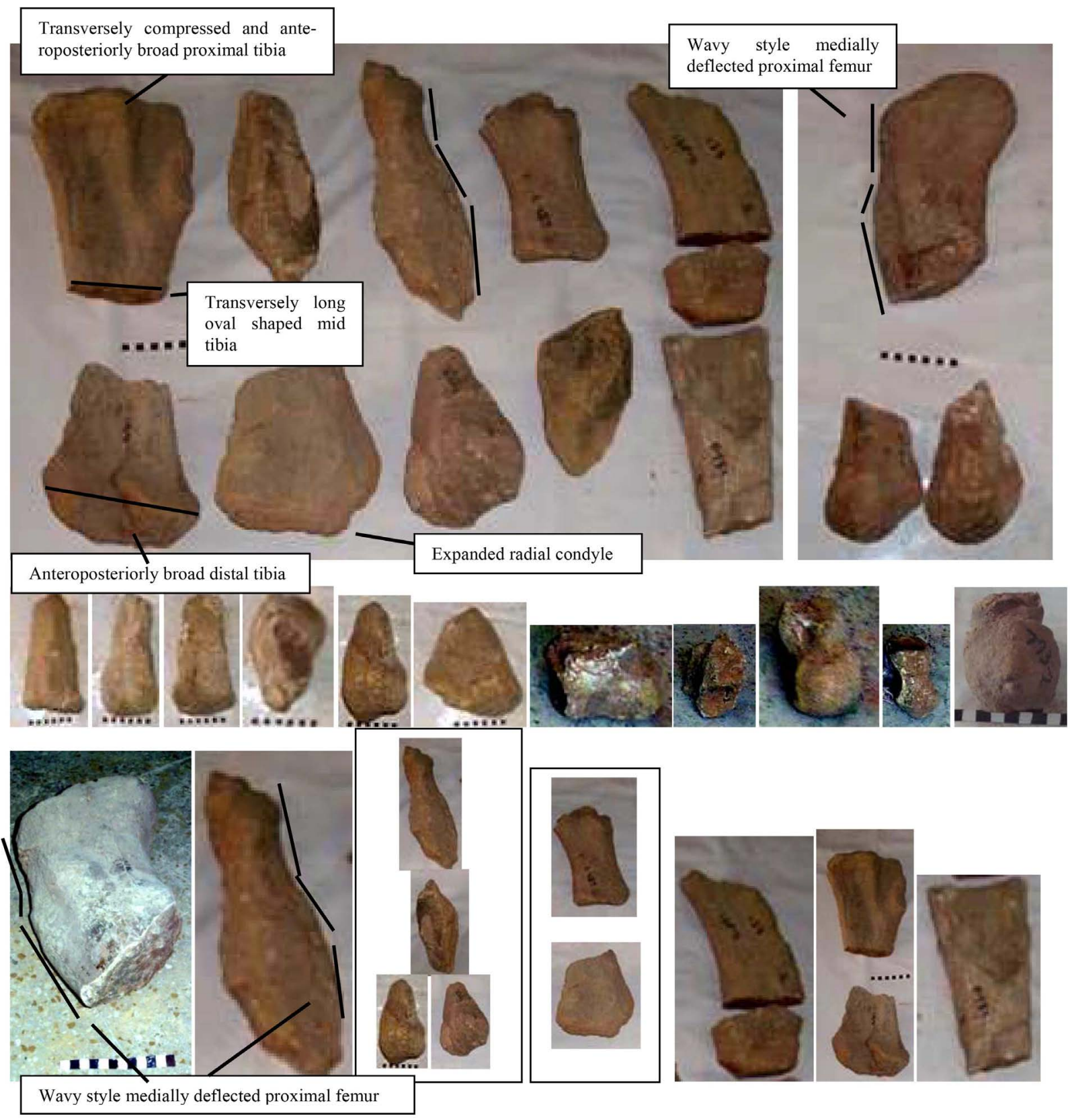

Figure 4. Pakisaurus balochistani associated skeleton from lower Bor locality. Row 1, p1, column 1, a partial right tibia including proximal slender tibia MSM-72-2 and distal tibia MSM-186-2; column 2, portion of proximal femur MSM-293-2 (may be adjusted with proximal and mid femur MSM-294-2); distal humerus MSM-180-2; column 3, proximal and mid femur MSM-294-2, part of distal femur MSM-266-2; column 4, mid humerus MSM-289-2, humerus part MSM-498-2; column 5, proximal partial humerus MSM-288-2 (proximal most and lateral part eroded), mid humerus MSM-290-2, mid tibia MSM-286-2; p2, proximal and mid femur (upper) MSM-69-2, with distal condyles MSM-272-2 and MSM-265-2 (lower); Row 2, p1, 2, 3, distal fibula MSM-183-2 in 3 views; p4, 5, 6, part of distal femur MSM-233-2 in 3 views; p7, 8, 9, 10, caudal vertebra MSM-16-2 in 4 views for scale see [9]; p11, caudal vertebra MSM-793-2. Row 3, p1, left proximal and mid femur MSM-69-2 in posterior view; p2, right proximal femur MSM-294-2 for scale see row 1; p3, right femur in proximal femur MSM-294-2, mid femur MSM-293-2 and distal femur MSM-266-2 parts, for scale see row 1; p4, proximal and mid partial humerus MSM-289-2 and distal humerus MSM-180-2 for scale see row 1; p5, proximal partial humerus MSM-288-2 (proximal most and lateral part eroded), mid humerus MSM-290-2 for scale see row 1; p6, a partial right tibia including proximal slender tibia MSM-72-2 and distal tibia MSM-186-2; p 7, proximal and mid left tibia MSM-286-2 for scale see row 1. Scale, each black or white digit is $1 \mathrm{~cm}$. 


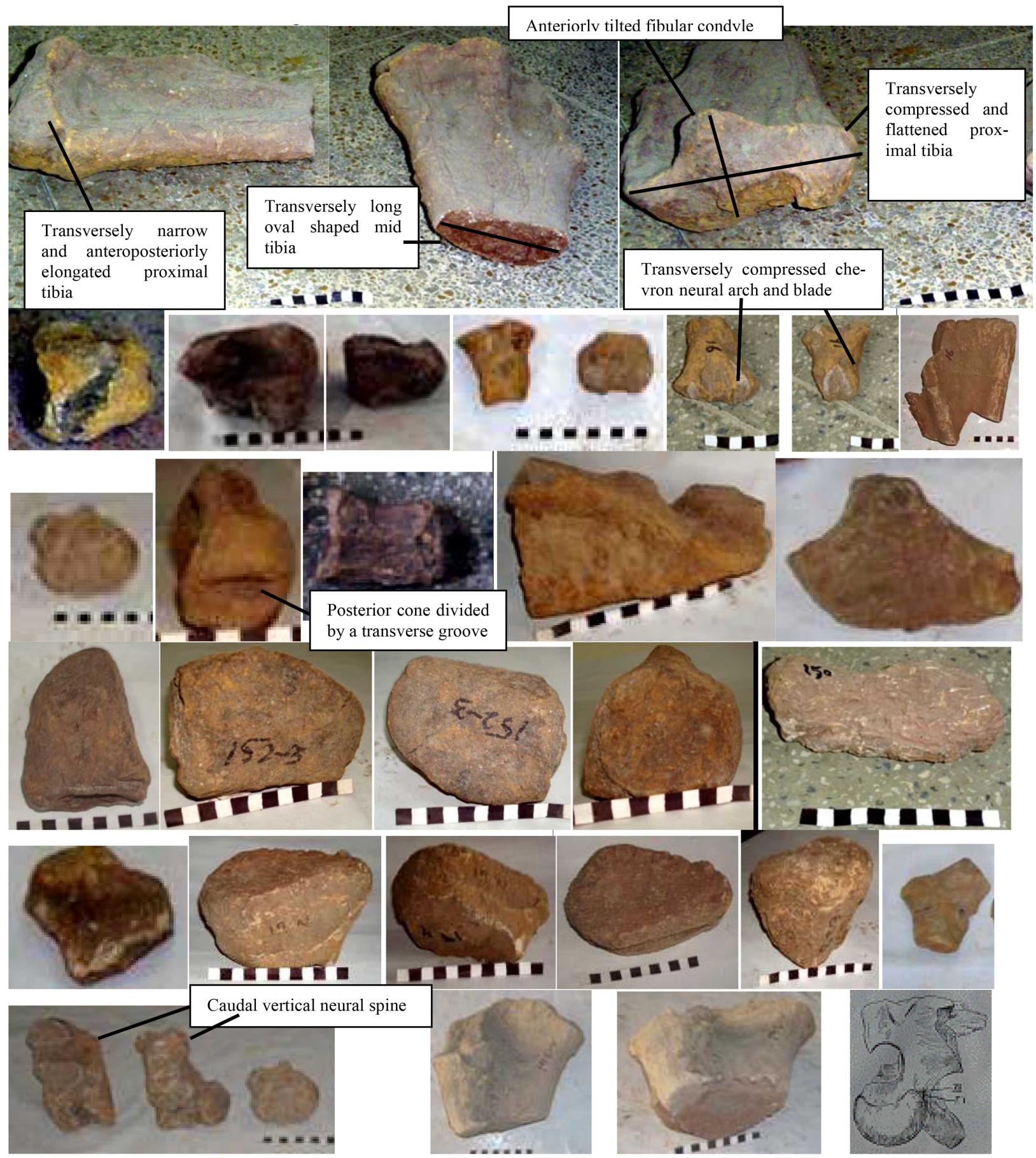

Figure 5. Pakisaurus balochistani referred materials (rows 1 - 6). Row 1, proximal slender right tibia MSM-72-2 in posterior, ventral and dorsal views. Row 2, caudal vertebrae MSM-17-16 for scale see [9], MSM-510-16, MSM-154-16; chevron MSM-330-16, prezygapophyses MSM-327-16; caudal chevron MSM-330-16 in 2 views; proximal ulna MSM-1032-16. Row 3, fractured distal caudal vertebra MSM-523-3; distal caudal vertebra with horizontal groove on posterior cone MSM-151-3 in posterior and lateral views; proximal pubis with glenoid and fenestra MSM-366-3; ulna MSM-748-3 for scale see [15]. Row 4, sickle shaped ungual MSM-152-3 in four views, possibly thick armour spine MSM-150-3. Row 5, proximal pubis MSM-403-19n for scale see [15]; proximal radius MSM-756-19n in 3 views; distal ulna MSM-628-19n; proximal rib MSM-321-13 from East Dolwahi for scale see [15]. Row 6, caudal vertebrae MSM-758-19n, MSM-1010-4 and MSM-523-3; proximal right humerus MSM-195-4 in anterior and anteroventral views; braincase GSI K27/497 [35]. Scale each black or white digit is $1 \mathrm{~cm}$. 
Formation which is capped by the upper sandstone unit of Vitakri Formation. The slender flattened tibia with anteroposteriorly broad distal end, humerus with expanded and anteriorly exposed radial condyle, and tall caudal vertebra of lower Bor locality are the major key elements for attribution to Pakisaurus balochistani. The humerus and caudal vertebra of lower Bor are overlapped with holotype (Figures 1-3) of Pakisaurus balochistani. The lower Bor skeletal key elements did not match to holotypic materials of Isisaurus colberti from Dangargaon, India [25], and referred lower Sangiali and Zubra peak skeletons [23] from Pakistan (Figure 6) of Isisaurus colberti pakisaurid slender Poripuch titanosaur, and Chota Simla skeleton from India [16] [21] [32] and Alam, Top Kinwa and Mari Bohri skeletons from Pakistan of Gspsaurus pakistani [20] [21], and north Kinwa and Mari Bohri skeletons and lower Sangiali fossils from Pakistan of Saraikimasoom vitakri [22] [23] gspsaurid stocky poripuchian titanosaurs. Further the holotypic (Figures 1-3) and lower Bor exemplar (Figure 4) skeletons bones are consistent with skeletons of other 3 recognized taxa from Indo-Pakistan. The holotypic (Figures 1-3) and referred (Figure 4, Figure 5) specimens from Pakistan are housed in the Museum of the Geological Survey of Pakistan, Quetta.

Some fossils from India referred to Pakisaurus balochistani [24] (and here) like an isolated tooth GSI 20,006 from Rahioli [33] [34]; braincase GSI K27/497 [35]; axis from Nand [36]; caudal vertebra K20/315, poorly preserved tibia K20/321 and fibula K27/489 from Bara Simla [35] [37]; caudal vertebra K27/504, braincase GSI K27/497 (Figure 5), caudal vertebra K20/317 and chevron from Bara Simla [35] and middle caudal vertebra (NHMUK R16481) from Chota Simla of Jainosaurus (=Antarctosaurus) septentrionalis [16]. The tall, flat sided and ventrally not reduced caudal vertebrae, slender flattened tibia and teeth with almost constant diameter are the key elements of Pakisaurus balochistani.

The Jainosaurus (=Antarctosaurus) septentrionalis limb materials from Chota Simla [16] [32] are referable to Gspsaurus pakistani due to its key element stocky proximal tibia. Further right scapula [35] of Jainosaurus (=Antarctosaurus) septentrionalis show affinity to Isisaurus colberti. The distinct part of distal humeri from India [35] destroyed and not preserved. In this way Jainosaurus (=Antarctosaurus) septentrionalis [35] bones show multiple taxa affinity and seems no stability. These Indian fossils are referred due to possible similarity with caudal vertebra (tall and the dorsal and ventral mid caudal width ratio 1) and flattened and transversely thin and narrow bone tibia and transversely narrow distal scapula. Braincase referred due to finding large sized and different than Gspsaurus and Saraikimasoom and also suggested by a few previous researchers. This materials from India referred to Pakisaurus balochistani due to tall midcaudal with ratio of mid caudal width above and below is about 1 i.e. in ventral view the dorsal width are not clearly observed [24]. The Pakisaurus named after the host country Pakistan and species $P$. balochistani named after the Balochistan province, Pakistan [8] [9].

Geological Formation and Age: The holotypic and referred materials were 
collected from the Latest Cretaceous (latest Maastrichtian; 67 - $66 \mathrm{Ma}$ ) Vitakri Formation of Fort Munro Group [14] from Pakistan [3] [4] [9] and Lameta Formation from India. The Pab Formation was divided into lower member Dhaola, middle member Kali and upper member Vitakri [3]. Later on the Vitakri Formation was established by [14] which include the meandering river deposits as sandstone units alternated by two overbank red, green and mottled coloured mud units. Two mud units of the Vitakri Formation (which is the upper part of previous Pab Formation) are the host of these fossils. Most of these fossils found as surface finds as clusters on the shale units, however a few were excavated partially and a few were found as isolated. Vitakri Formation varies from 1 $\mathrm{m}$ to $35 \mathrm{~m}$ in thickness deposited by alluvial fresh water terrestrial deposits. In Sulaiman (middle Indus) basin where these bones are found so far, the Vitakri sediments consist of two red mud units (mostly red and maroon shale with subordinate green and khaki shale) of over bank deposits and two sandstone units (thin to thick bedded, grey to white muddy quartzose, not clean) of meandering river channel deposits. The lower red mud units-over bank deposits (4-14 m), middle sandstone unit (3 - $4 \mathrm{~m})$, upper shale/mud unit (3 - $11 \mathrm{~m})$ and upper sandstone unit $(4-7 \mathrm{~m})$ are found in the eastern Sulaiman foldbelt [3]. At places the shale units and the middle sandstone unit is covered by scree. The Vitakri Formation (Ziarat laterite) is $0.3 \mathrm{~m}$ to $2 \mathrm{~m}$ in the Ziarat and Sanjawi areas of Ziarat district [3] while it is $1 \mathrm{~m}$ thick (laterite and carbonaceous shale just like of latest Cretaceous Kingri coal of Vitakri Formation in eastern Sulaiman Basin) exposed in the Sor Tangi section of Zhob district located between Musafar Pur to Mina [38] [39], as tectonic set up Sor Tangi is located at the western extremity of Western Indus Suture and eastern extremity of North Balochistan basin. The Vitakri Formation is about 30 - 35 m thick (red sandstone with minor red muds) in the Bara and Khadro sections of Laki thrusted anticline, Sindh Province, southern Pakistan. The lower contact of Vitakri Formation found with Dhaola member of Pab Formation (white colored washed sandstone of Pab Formation in eastern Sulaiman) and Kali member of Pab Formation (only difference is the red and maroon muds of Vitakri Formation and stratigraphic position) in western Sulaiman foldbelt and upper contact with marine limestone and green shale and sandstone of Sangiali Formation or Rakhi Gaj formation in Sulaiman basin and Khadro or Bara Formation in eastern Kirthar basin. The Vitakri Formation in Laki anticline of eastern Kirthar (Sindh Province) is typically represented by red to brown colored sandstone and shale which has lower contact with white colored sandstone of Pab Formation, exposed in the thrusted core of Laki anticline [26]. The Sangiali and Khadro formations are found clearly only in type sections, in other places their finding and identifications are difficult. However the Rakhi Gaj Formation is well exposed in Sulaiman and western Kirthar basins while its coeval Bara Formation is well exposed in eastern Kirthar. The lower contact of Vitakri Formation (Ziarat laterite) found with Parh Limestone and upper contact with marine limestone of Dungan Formation in Sanjawi-Ziarat 
areas. The lower contact of Vitakri Formation found with Pab and upper contact with Paleocene Nisai Limestone in Sor Tangi section of Zhob District. The equivalent of Vitakri formation in Upper Indus basin is Indus Formation (Latest Cretaceous and Infra Tertiary boundary; laterite, bauxite, glauconite and chamosite; previously a part of basal Hangu Formation).

Pakistan is the best place for the study of KT mass extinction and latest archosaurs and other biotas from where the latest archosaurs (titanosaurian sauropod and theropod dinosaurs, mesoeucrocodiles) and other biotas became extinct and the existing of wide exposures of marine and non-marine KT or KPg boundary. The characters of the latest titanosaurs and other archosaurs and biotas, end Cretaceous their mass extinction, wide exposures of terrestrial and marine Cretaceous-Tertiary boundary/KT boundary or Cretaceous-Paleogene boundary K-Pg boundary and dispersal of Cenozoic biotas from Pakistan have attracted the world scientists. In the eastern surrounding areas of Balochistan, the south Punjab also host the Vitakri Formation (and its vertebrates) exposed in Rakhi Gaj area and Mian Ghundi anticline in the Khar Fort Munro area of Dera Ghazi Khan, and Chitri and Dragal-Maarri areas of Rajanpur district, south Punjab.

Reference [40] reported Orbitoides (Lepidorbitoides) minor from lower part of the unit (Pab and Mughalkot formation) in Rakhi Nala representing early Maestrichtian age. Reference [41] reported mixed benthonic-pelagic foraminifers of Maastrichtian age from type locality area of Pab Formation. Reference [42] reported Globotruncana aff. G. linnei, Lituola sp., Omphalocyclus macropora, Orbitella media, Orbitoides sp., Siderolites sp., from Moro area in Moro $(=\mathrm{Pab})$ formation with Maestrichtian age. According to dinosaur and associated vertebrate fossils, stratigraphic position and previous work, the reference [43] considered the age of Vitakri Formation as latest Maastrichtian or latest Cretaceous (67 - $66 \mathrm{Mya} /$ Million years ago) [44]. The Lameta Formation from India (coeval of Vitakri Formation from Pakistan) is the host of latest Cretaceous vertebrates from India. Its age latest Maastrichtian (67 - $66 \mathrm{Mya}$ ) is based on the microfossils, vertebrates, and the associated basal flows of the Deccan lavas [1] [45] [46].

\subsection{Diagnosis of Pakisaurus balochistani}

Pakisaurus balochistani is a large sized gracile bodied pakisaurid Poripuchia titanosaurian sauropod sharing with the Titanosauria as procoelous caudals, forward insertion of neural arches on caudals, vertebrae lacking hyposphene-hypantrum articulations, prominent olecranon process on ulna and neural spine single and not bifid. Pakisaurus balochistani shares with Poripuchia [4] [27] as procoelous all caudal vertebrae except first biconvex in some taxa (because in Poripuchia anterior, middle and distal caudals found are all procoelous, while in lithostrotian distal caudals are not procoelous). Pakisaurus balochistani sharing with the Pakisauridae (characters same as genus and species Pakisaurus balochistani) as straight and slightly recurved slender teeth which have almost same thickness 
(diameter) except tip (opposite of gspsaurids teeth which are conical and converge and taper on all sides from base to tip); ratio of mid transverse width above and below of mid caudal centrum is about 1 i.e. the ventral view of mid caudal centra are not compressed or slightly compressed; transversely (relatively) thin bone of proximal tibia; proximal tibia, anteroposteriorly twice wide than transverse width (in Gspsauridae stocky tibia anteroposteriorly 1 to 1.5 times than transverse width); distal tibia is anteroposteriorly more wider than transverse width (while in Gspsauridae distal stocky tibia is transversely more wide than anteroposterior width). Pakisauridae is the most inclusive clade of Titanosauria containing Pakisaurus balochistani and Isisaurus colberti but not Saraikimasoom vitakri and Gspsaurus pakistani.

Pakisaurus balochistani is characterized by long slender legs and tall tail; narrow, long and recurved teeth with constant thickness from base to tip (except tip) and slender indices more than 5 (while Gspsaurus and Saraikimasoom have moderate and small teeth respectively with gradually decreasing thickness from base to tip, and have rounded and pointed tips and slender indices vary from 3 5); large sized braincase with D-shaped occipital condyle (Figure 5) (while Gspsaurus and Saraikimasoom have rectangular occipital condyle with sagital dorsoventral groove and constriction); basal tubera breadth narrower than occipital condyle; caudals are tall (Figure 1) quadrangular shape (without significant ventral reduction) except a few anteriormost caudals which are broad; vertically oriented neural spine (Figure 1) on anterior and mid caudals (unlike Isisaurus colberti show inclined neural spine); distal most caudal centrum anterior articular face shape procoelous while posterior face ball has a horizontal transverse groove in the middle (posterior ball is folded like upper and lower anticlines alternated or sandwiched by a mid syncline) (Figure 5) unlike the slight and very feeble vertical groove on posterior ball of distal caudal centrum of Lirainosaurus astibiae [47] from Spain, Europe and U-shaped groove on posterior ball of distal caudal centrum of Epachthosaurus sciutoi [48] from Patagonia, Argentina, South America; Anterolateral bicleavage of sternal or two longitudinal transverse crest separated by a trough and medially convex profile (Figure 3); distal scapula relatively less expanded (Figure 2) than Gspsaurus pakistani and Saraikimasoom vitakri; distal scapula with relatively anteroposteriorly long glenoid (Figure 2); distal scapular articular length for coracoid is relatively small (Figure 2) (unlike Isisaurus which have long articular surface for coracoid); acromian process is narrow (Figure 2); expanded radial condyle exposed on the anterior aspect of distal humerus (Figure 1) (Figure 4) (unlike Isisaurus colberti which have no expanded radial condyle); femoral shaft, lateral margin shape, proximal one-third deflected medially with wavy style (Figure 4) (and not straight as in Saraikimasoom vitakri); slender flattened and transversely compressed proximal tibia with anteroposteriorly quite broad distal tibia (Figure 4), (while Gspsaurus pakistani have stocky biconvex lense shaped tibia with transversely broad distal ends, $\mathrm{Sa}$ raikimasoom vitakri have stocky subsquare shaped proximal tibia of equal trans- 
verse and anteroposterior widths, Isisaurus colberti have slender flattened and transversely compressed proximal tibia with anteroposteriorly relatively less broad distal tibia; Figure 7); and dorsoposterior to lateroventrally oriented crest or ridge on the medial aspect of proximal fibula; and dorsoventrally straight parallel rugose structures on proximal fibula (Figure 2).

Extension of Procoely from anterior caudals to distal caudals-a discussion: Reference [49] mentioned "Procoely in anterior caudal vertebrae has traditionally been regarded as a derived titanosaur feature, with this convergently present in Mamenchisaurus and flagellicaudatans" [50]-[55]. However, mild procoely is present in the anterior caudal vertebrae of the basal titanosaur $A n$ desaurus [56], as well as the somphospondylan Tastavinsaurus [57], and the non-titanosaurian Dongbeititan possesses strongly procoelous anterior caudal vertebrae [58]. Furthermore, a number of probable non-neosauropods also display strongly procoelous anterior caudal vertebrae [i.e. Bellusaurus [59], Chuanjiesaurus [60], HMN MB.R.2091.1-30 [49] [61], and Losillasaurus [62]. Similarly, the extension of procoely into middle-posterior caudal vertebrae has been considered a feature of lithostrotian titanosaurs [51] [52] [53] [54] [55]. Although its uninterrupted presence still remains a feature of derived titanosaurs, the possession of some procoelous middle caudal vertebrae is much more widespread amongst titanosauriforms. Some middle caudal vertebrae referred to the Late Jurassic brachiosaurid Giraffatitan ([63]: pl. 3, fig. 22; HMN MBR specimens: P. D. Mannion, pers. observ., 2011) display the procoelous condition [64] [65], and a number of taxa of uncertain taxonomic affinities within Somphospondyli [49] also display this morphology [e.g. Brontomerus [66], Gobititan [67], Malarguesaurus [68], Astrophocaudia [65], and Tastavinsaurus [69]". Although the farthest vertebra are not procoelous in Lithostrotia, the titanosaurs from India and Pakistan represent procoelous distal caudal vertebrae especially distal caudals which are found so far. So the author suggests the extension of procoely into middle and posterior caudal vertebrae has been considered a feature of Poripuchia [4] [27] titanosaurs. Poripuch is the Saraiki language word means full tail (with procoelous vertebrae). The Poripuchia titanosaurs consist of all procoelous caudals including the distal caudals also, however in some taxa the first caudal is biconvex. In pakisaurids and gspsaurids all the caudal vertebrae found so far belong to anterior, middle and distal caudal vertebrae are procoelous (except first biconvex caudal). The Poripuchia is the most inclusive clade of Titanosauria containing all caudal procoelous (except first biconvex caudal in few taxa). The Poripuchia is the most inclusive clade of Titanosauria containing Pakisaurus and Isisaurus of pakisaurids, and Gspsaurus and Saraikimasoom of gspsaurids the derived titanosaurs.

\subsection{Description of Fossils of Pakisaurus balochistani}

\section{Cranial elements}

The long, narrow and recurved tooth GSI 20,006 from India [33] with con- 
stant thickness from base to tip (except tip) was referred to Pakisaurus balochis$\operatorname{tani}[22]$ due to following reasons and evidences. The teeth articulated with snout and rostrum of Gspsaurus and Saraikimasoom are different with each other. Gspsaurus and Saraikimasoom have teeth with gradually decreasing diameter toward tip while the tooth GSI 20,006 from India [33] has constant thickness from base to tip (except tip). So it is not referable to Gspsaurus and Saraikimasoom. It is only referable to Pakisaurus and Isisaurus colberti. Further the Pakisaurus balochistani has typical flattened tibia and typical humerus more similar to Rapetosaurus krausei from Madagascar. The tooth GSI 20,006 from India [33] and the tooth of Rapetosaurus krausei are also similar in nature [70]. So it also helped again to assign this tooth GSI 20,006 to Pakisaurus balochistani.

The braincase GSI K27/497 (Figure 5) along with left and right scapula and two right humeri was assigned to Jainosaurus (=Antarctosaurus) septentrionalis [35]. This braincase GSI K27/497 was referred to Pakisaurus balochistani [22] due to large size with D-shaped with ventrally convex condyle and distinguished from subrectangular shaped with ventral groove in the lower centre forming W-shaped condyle of braincases of Gspsaurus and Saraikimasoom, and D-shaped with ventrally convex condyle small sized braincase of Isisaurus. The braincase of Pakisaurus balochistani is a large in size like its stocky cousin the Gspsaurus pakistani. Main features of braincase GSI K27/497 are as follows [22] [35]. Large sized braincase; D-shaped with ventrally convex condyle (unlike the Gspsaurus and Saraikimasoom which have subrectangle shaped occipital condyle with median ventral groove producing its $\mathrm{w}$-shaped); Occipital condyle is large and broad and greater part of its convexity faces downward; Occipital condyle broad flat upper surface forms the medulla oblongata and foramen magnum; The thick ball of the condyle sharply defines from its narrower neck; Basal tubera breadth, narrower than occipital condyle; Occipital region of skull shape, flat and distally recurved; Paroccipital processes oriented transversely; Basal tubera are long process, diverging laterally with relatively lower angle (than its stocky cousin the Gspsaurus pakistani who have high angle basal tubera); Basal tubera directed slightly backwards; From the large basal tubera the basipterygoid processes branch off; and Basipterygoid processes diverge somewhat anteriorly and much longer than the basal tubera but their ends are not preserved [35].

\section{Vertebrae}

The axis centrum (Nand axis; 196/CRP/GSI/05 [36]) from India is being referred to Pakisaurus balochistani on the basis of cervical vertebral morphology and distinguishing from Gspsaurus axis (articulated atlas-axis from Pakistan [12] [21]). This Pakisaurus axis is taller than broad anteriorly and broad than tall posteriorly, relatively elongate, with its length more than twice its height and pneumatic or spongy [36]. More characters of Pakisaurus axis can be seen in [36] and Gspsaurus axis can be seen in [12] [21]. The other member of gspsaurids from Indo-Pakistan is the Saraikimasoom vitakri [22] [23] who is small in size while the axis proportions show its assignment to medium presacral remains 
which are not yet known for Jainosaurus (=Antarctosaurus) septentrionalis. Axis remains are not reported for Isisaurus colberti. The postaxial cervical vertebrae of Isisaurus colberti do not exhibit the marked external pneumatic structures present in the Nand axis, which suggests that it pertains to a different species. It is anticipated that the Nand axis pertains to a titanosaur with a high degree of external pneumatization apparent throughout the cervical series [36]. So the above statement of [36]) conveys that Nand axis is expected to belong to Pakisaurus balochistani pakisaurids the slender titanosaurs who have pneumatic presacral vertebra, matching of pleurocoel shape, proportion, etc and again different from gspsaurids axis.

The cervical vertebrae are broad, long and opisthocoelous (Figure 1). The vertebrae represent the camellate/spongy/pneumatic texture and elongated lateral pleurocoel. The pleurocoel is thick anteriorly and relatively thin posteriorly. The neural spine seems to be undivided. The broken vertebrae represent the external and also internal spongy/pneumatic texture. Parapophyses are located on the anterior of pleurocoel of cervicodorsal vertebra. This cervicodorsal centra are broad (height is less than width) and relatively less longer than cervical. In general length is more than width. The centra are strongly opisthotic and have single rounded pleurocoel and ventral flat surface. The dorsal vertebrae are slightly broad, slightly long and opisthocoelous (Figure 1). The dorsal centrum is relatively less broad and less long and higher than cervical vertebrae. The pleurocoel is single, relatively short and anteriorly slightly wider (dorsoventrally) than posteriorly. The broken vertebrae represent the external and also internal spongy/pneumatic texture. There is no hyposphene-hypantrum articulation. The proximal portion of dorsal rib is pneumatic. The coosified two sacral vertebrae are broad and pneumatic.

Anterior caudal centra have no pleurocoel. Anterior caudal transverse processes proximal depth, deep, extending from centrum to neural arch. Anterior caudal transverse processes shape, subcircular shaped extending to neural arch forming belt. Anterior and middle caudal centra, shape, quadrangular, groove ventrally, flat laterally and ventrally not reduced. Vertically oriented neural spine (Figure 1) on anterior and mid caudals (unlike Isisaurus colberti and Saraikimasoom vitakri both show posteriorly inclined neural spine). Anterior and middle caudal centra have ventral longitudinal hollow. Anterior, middle and posterior caudal centra, anterior articular face shape procoelous (a feature of poripuch titanosaurs). Posterior caudal centra, shape is slightly tall. Posterior caudal centra long, tall, without ventral groove and chevron ridges. Mid and posterior caudal centra lateral surfaces not visible or slightly visible in the mid and posterior caudals (while prominent visible in Gspsaurus and most prominent visible in Saraikimasoom). All found caudal centra are procoelous. Anterior concavity is deep and well rounded. Posterior convexity are strongly pronounced cone like established dorsally and tall to squarish rectangular. Lateral surfaces are not compressed in anteriormost caudal centra. Mid caudals, the chevron facets on the 
posterior rim are located on a raised prominent ridge. Chevron facets on the anterior rims are located on comparatively very low, faint ridges and sides are slightly compressed. Neural arches are hosted on the anterior portion of centra.

Anterior caudals are slightly broad to tall, lateral upper half (just below the transverse process) flat sided and without ventral groove and chevron ridges. Mid-caudals are long, tall, waisted and flat sided having a ventral groove bounded by chevron facets. The measurements of some caudal vertebrae are shown in table 1 of [9]. Distal caudal is slightly tall. Mid and posterior caudals ratio of mid-dorsal width to mid-ventral width is about 1 . Lateral surfaces on ventral view are partially visible in the anterior caudals and not visible or slightly visible in the mid and posterior caudals. Neural spines are single (not bifid). Posterior convexity are strongly pronounced cone like and slightly tall rectangular. Anterior caudal have started posterior chevron facets. Mid caudals chevron facets on the posterior rim are located on a raised prominent ridge but the chevron facets on the anterior rims are located on comparatively very low, faint ridges and sides are slightly compressed. Neural arches are hosted on the anterior portion of caudal centra. Prominent rib facets/transverse process occurs at the junction of the centrum and the neural arch in the anterior/mid caudals. Anterior most caudals are broad while remaining all caudals is tall. Midcaudals have posterior ball cone situated and shifted dorsally above the centre (cone above the dorsoventrally oriented centre). Anterior or middle caudal chevron arch and chevron blade are transversely compressed (Like Isisaurus colberti [25]. Chevron haemal canal (of anterior/mid caudals) is about half of the chevron length. Chevron haemal canal (of anterior/mid caudals) is deep. Proximal chevron division is V-shaped. Chevron is simple. Chevron proximal "crux" bridging superior margin of hemal canal is absent. Anteriorly directed process of Middle and distal chevron blades is absent. Posterior chevron distal contact is open (not fused with other chevron). The distalmost caudal centrum (Figure 5), anterior articular face shape procoelous while posterior articular face ball has a horizontal groove on the mid of cone creating bifurcation or divided the ball in to two crests or anticlines sandwiched by a groove or syncline, it is a unique and unusual feature. The slight and very feeble vertical groove on posterior ball of distal caudal centrum is reported from Lirainosaurus astibiae [47] from Spain Europe and U-shaped groove on posterior ball of distal caudal centrum Epachthosaurus sciutoi [48] from Patagonia, Argentina South America.

The Pakisaurus referred caudal centrum (NHMUK R16481) collected by Matley 1930s from Chhota Simla India [16] has elemental dimension like length 14.9 $\mathrm{cm}$, anterior face height $11.5 \mathrm{~cm}$, anterior face width $10.3 \mathrm{~cm}$, estimated posterior face height $10.5 \mathrm{~cm}$ and posterior face width $9.5 \mathrm{~cm}$ [16]. These measurements matches with caudal vertebra of Pakisaurus can be seen Table 1 of [9]. This caudal vertebra considered associated with some limb elements [16]. While this vertebra shows affinity to Pakisaurus balochistani and other associated limb elements from Chota Simla [16] [32] belong to Gspsaurus pakistani due to typi- 
cal tibia. According to [16] this caudal vertebra have a conical posterior convexity, a posteroventrally beveled anterior articular concavity, and a marked ventral hollow which is different than Isisaurus colberti. Gspsaurus and also Saraikimasoom mid caudal vertebrae show some ventral reduction and significant ventral reduction respectively which is not found in this Chota Simla vertebra. Its tallness, planar lateral surface and no ventral reduction revealed affinity to Pakisaurus balochistani.

\section{Appendicular and limb elements elements}

Sternal Plate: The sternal (anterolateral sternal MSM-355-4 and medial sternal convex MSM-598-4; Figure 3) was collected from south Kinwa 4s. Sternal plate, shape seems to be crescentic with concave lateral border and convex medial border. The anterolateral edge is maximum thick $6 \mathrm{~cm}$ with concave anterolateral border and has anteroventral crest and becoming gradually thin as proceeding posterior and medial directions. The anteroventral crest is diminishing as proceeding posteriorly. There are rugosities on the anterior, anterolateral, anteromedial of anterior of sternal plate. But the intensities of rugosities and thickness on anteroposterior edge of sternal plate of Pakisaurus balochistani are less than the Saraikimasoom vitakri. The Pakisaurus balochistani sternal plate MSM-355-4 is relatively slender and $6 \mathrm{~cm}$ thick with feeble rugosities on the anterolateral edge while the sternal plate MSM-675-15 of the Saraikimasoom vitakri is relatively robust and stocky and $7 \mathrm{~cm}$ thick with strong dorsoventral rugosities on the anterolateral edge. These rugosities show connection with the scapular coracoid region and other fellow. The anteroventral crest is constricted dividing into lower and upper plates like structures. The upper and lower plates show cleavage like structures. Both plates have depressed line in between these plates. The plate is slightly concave on the ventral and dorsal sides. The anterolateral part is thick and sub rounded. From this thick corner the thickness is consistently reduced in the medial side. The anterior end is thickened by an obtuse ridge, which extends over the ventral side for about a decade centimeter. The medial side plate is convex and slightly expanded and rugose for the attachment of fellow. As a whole the medial plate is relatively thin as compared to anterolateral part.

Scapula: A pair of scapula (proximal scapula MSM-318-4, MSM-319-4, mid scapula MSM-590-4, MSM-593-4; left mid scapula MSM-203-4 and right mid scapula MSM-198-4, right distal scapula with glenoid surface MSM-205-4 and left distal scapula with glenoid surface MSM-162-4; Figure 2) were collected from south Kinwa 4s. The dorsal view of proximal scapula has rugosities on the uppermost edge line. Scapular acromian blade and process (including glenoid, articular surface for coracoid and acromian process, all size, broad, width about $150 \%$ minimum width of blade. Scapular acromian process only size is narrow. Scapular blade, shape, acromial edge rounded with slight expansion on acromial side. Mid scapular blade, cross-sectional shape is D-shaped. Distal scapula is expanded and represents broadening and thickening at the distal end forming a 
deep and spoon shape glenoid for humerus head, and nearby ruggosities for the attachment of coracoid. Distal scapula is maximum thick at about the center of the glenoid area where it forms ridge on one side and plain on other side. Distal scapula and coracoid are separate. The distal scapula of Pakisaurus balochistani are slender and deflected laterodorsally, and expanded in the lateroventral side of mid scapular blade, while the distal scapula of Saraikimasoom vitakri is stocky and not deflected laterodorsally i.e. it is straight or slightly deflected medially, and also not expanded in the lateroventral side of mid scapular blade. The distal scapulae of Pakisaurus balochistani, Saraikimasoom vitakri and Gspsaurus pakistani have relatively shorter articular surface for coracoid while Isisaurus colberti has relatively long articular surface for coracoid. The Pakisaurus balochistani distal scapula MSM-162-4 of Kinwa 4, anteroposterior width is $32 \mathrm{~cm}$ while depth is $12.5 \mathrm{~cm}$ which is maximum at glenoid. The stocky ratio width/length become 0.39 for Pakisaurus balochistani. Gspsaurus pakistani distal scapulae are relatively more stocky than Pakisaurus balochistani. The Gspsaurus pakistani distal scapula of Mari Bohri 15 anteroposterior width is $36 \mathrm{~cm}$ while depth is $18 \mathrm{~cm}$ which is maximum at glenoid. The stocky ratio width/length of Mari Bohri exemplar of Gspsaurus pakistani becomes 0.5. The Gspsaurus pakistani distal scapula of Topkinwa 16 anteroposterior width is $25 \mathrm{~cm}$ while depth is $12 \mathrm{~cm}$ which is maximum at glenoid. The stocky ratio width/length of Topkinwa 16 exemplar of Gspsaurus is about 0.48 .

Humerus: A pair of humeri (left and right humerus) including one complete while other partial humerus were collected from South Kinwa 4 (proximal right humerus MSM-202-4, mid humerus MSM-268-4, distal humerus MSM-193-4; Figure 1). Further a pair of humeri including partial left and right humerus (proximal and mid partial humerus MSM-289-2 and distal humerus MSM-180-2; proximal partial humerus MSM-288-2 and mid humerus MSM-290-2; Figure 4) localities. The humerus from South Kinwa (Figure 1) (Figure 3) is almost complete while the humerus of lower Bor has proximal end missing while the distal humerus is preserved and provide the key information regarding the anteriorly expansion of radial condyle. Proximal and distal humerus has rugosities. Proximal humerus has a posterior dorsoventrally central ridge (ventrodorsally oriented convexing part) on the posterior view. Proximal humerus has prominent lateral process than medial process. Humerus head and posterior convexity peak axis lies in medial half which makes the medial limb short (transversely) and lateral limb long (transversely). Deltopectoral fossa is relatively deep and open. Posterior central ridge (ventrodorsally oriented) is prominent in Pakisaurus balochistani while it is not prominent in Isisaurus colberti and also not prominent and V-shaped plain forming in Saraikimasoom vitakri. Radial condyle or thick ridge on the opposite side of ulnar adjustment concavity or cavity of distal humerus is expanded and anteriorly exposed. The more expanded and anteriorly exposed radial condyle than ulnar condyle found in Pakisaurus balochistani, while it is not found expanded radial condyle on the distal humerus in Isisaurus 
colberti. An anteriorly expanded radial condyle situated in the nearly transverse centre of anterior side of distal humerus in Pakisaurus balochistani, while it is shifted in the lateral pole of anterior side of distal humerus of Saraikimasoom vitakri. Distal humerus have broader open concavity or cavity for the adjustment of ulnar olecranon process in Pakisaurus balochistani, but more deep, close and less broad in Saraikimasoom vitakri. Humeral distal condyle, shape divided but ventrally horizontal flat surface. Humerus has well differentiated distal radial and ulnar condyles (unlike Isisaurus colberti). Humeral midshaft cross-section is elliptical with long axis orientated transversely. Humeral distal condyles, articular surface shape, restricted to distal expanded portion of humerus. Humeral distal condyle, shape is divided.

Radius: Proximal radius MSM-756-19n (Figure 5) from north Alam 19n and holotypic distal radius MSM-159-4 (Figure 2) from south Kinwa were collected so far. The radius proximal end surface is slightly concave and oval shaped due to close articulation with fibular condyle of distal femur while proximal end surface has flat oval-shaped outline in Lusotitan atalaiensis [49]. The radius proximal end surface has a well-developed medial projection like Lusotitan atalaiensis [49]. The proximal part show slight concavity or depression on proximal view. The proximal end is expanded and has pointed projection directed medially. The proximal radius has rugosities on the dorsal view and also extending somewhat down. The rugose distal end surface is subrectangular and slightly convex. Radius shaft is nearly oval upto preserved shaft section. The distal end of radius is expanding well. The distal end is sub rectangle type. The distal end is expanded and is directed downward medially or makes medial inclination on the axis of length of radius bone. It also shows some smooth surface but little bit outward which host the polygon of skin impressions or may be rugosities. This polygon type rugosity represents attachment surface of interosseus ligaments. The distal radius show prominent ridge having polygon type rugosities. Distal condyle flattened posteriorly and articulated in front of ulna. Radius shaft is nearly oval upto preserved shaft section. Radius distal breadth is approximately twice the shaft breadth. Radius, distal condyle orientation, beveled approximately $20^{\circ}$ proximolaterally relative to long axis of shaft. Radial distal condyle, shape is subrectangular, flattened posteriorly and articulating in front of ulna. Radius, distal breadth is approximately twice midshaft breadth.

Ulna: A pair of ulna (proximal left ulna MSM-603-4 and proximal right ulnae MSM-600-4, one ray of proximal ulna MSM-211-4; Figure 3) found from south Kinwa and a proximal ulna MSM-1032-16 from Top Kinwa 16 found so far. The proximal ulna and distal ulna are sufficiently preserved to convey significant relevant features. The proximal ulna is rugose with a prominent olecranon process. The proximal ulna has triradiate structure with three faces. One process is longer than other two. Proximal ulna is expanded well. There is a marked concave depression on the proximal lateral side to cradle the head of radius. It has also depression on the medial side also. The posterior side has slight depression and 
almost smooth surface. The ulna gradually tapers toward down. The distal end is smaller than the proximal end. The proximal end is relatively well and more expanded than minimum shaft, while distal end is slightly or little expanded than adjoining minimum shaft. The distal shaft is subcircular. Ulnar proximal condyle, shape is triradiate, with deep radial fossa.

Metacarpals: Partial metacarpals MSM-280-4 and MSM-970-4 (Figure 2) were collected. Its dorsal view is generally triangular. Its shaft seems long. The distal end is slightly expanded but without rugosities, showing loss of phalanges and unguals. Metacarpal condyle shape is undivided. Metacarpal condyle is convex type. Metacarpal distal condyle, transverse axis orientation, beveled approximately $20^{\circ}$ proximodistally.

Ilium: The preacetabular process of ilium (proximal anterior process of ilium MSM-971-4 and MSM-972-4; Figure 2) is thick, massive and platy. While the posterior part of ilium (MSM-806-4; Figure 2) is relatively thin and also seems to be spongy. Iliac preacetabular process shape triangular and thick plate. Further the posterior part of ilium (MSM-806-4; Figure 2) represents rod type projection. This rod type posterior projection of ilium may be the remnants of a sacral rib. This rod type projection is also found in the Lusotitan atalaiensis [47].

Pubis: The preserved specimen has only proximal part of pubis glenoid area with fenestra MSM-366-3 (Figure 5) collected from Shalghara 3. The glenoid area is maximum thick and become thin abruptly in the other area. Over the glenoid area, there is a thickening of the bone which sharply falls on the plate. A fenestra found close to glenoid end is also found. The glenoid is transversely thick and concave with an oval outline. The fenestra has an elliptical outline, with the maximum diameter anteroventrally-posterodorsally oriented. This fenestra completely encircled by bone.

Femur: Partial right femur (proximal and distal femur MSM-595-4 and MSM-200-4; Figure 2) found from Kinwa 4 and a pair of femora (proximal and mid left femur MSM-69-2, with distal condyles MSM-272-2 and MSM-265-2; Figure 4), and partial right femur (proximal and mid femur MSM-294-2 and part of distal femur MSM-266-2; Figure 4) found from lower Bor 2 locality which host the associated typical transversely thin and anteroposteriorly broad tibia and also typical distal humerus with other bones. The lower Bor femur (Figure 4) is relatively small which may belongs to subadult than the Kinwa femur (Figure 2) which belong to adult. The femoral head along with greater trochanter is anteroposteriorly compressed in contrast to the Saraikimasoom vitakri and also possibly Gspsaurus pakistani have rectangle shaped proximal femur. The preserved sector of the diaphysis is anteroposteriorly compressed, resulting in an elliptical outline, which have about 3 times mediolateral width than anteroposterior width while Saraikimasoom vitakri and possibly Gspsaurus pakistani have about 2 times mediolateral width than anteroposterior width. The tibial condyle is bigger and transversely longer than the fibular one. The epicondyle is well developed and separated from the fibular condyle by a well-defined prox- 
imodistal groove. The proximal and distal ends are relatively anteroposteriorly less expanded than Gspsaurus and Saraikimasoom gspsaurids. The prominent feature observed here is the presence of upper one third deflection (unlike Saraikimasoom and Gspsaurus which have proximal femur straight and not deflected medially). But the lateral profile of proximal deflection is wavy type in Pakisaurus and straightly inclined in Saraikimasoom vitakri. The proximal femur also forms very gentle arc or curve on medial side of proximal shaft and in middle and lower part shaft becomes straight. Below the proximal deflection, the shaft of the femur is straight in both anterior and lateral views. A prominent dorsoventrally longitudinal ridge started from the posterolateral corner of greater trochanter and extends down upto mid femur and may be further downward. This ridge is sub parallel ridge to medial and lateral sides. The fourth trochanter is feebly recognized on the medial side where the proximal one third is deflected medially. The shaft section observed just little above the mid shaft is elliptical but slightly concave anteriorly and convex posteriorly. The proximal end of the femur extends dorsomedially as extended subrounded head. The greater trochanter forms the proximolateral corner of the proximal femur. The distal half of the femur is slightly narrower transversely than is the proximal half (Figure 2). The distal end is bifurcated in two condyles as tibial and fibular condyles both have rugosities on ventral view. Femoral fourth trochanter is reduced to low crest or ridge. Femoral midshaft, transverse diameter is more than twice of anteroposterior diameter. Femoral shaft, lateral proximal one-third deflected medially (lateral wavy profile); Femoral distal condyles, ventrally more expanded tibial condyle than fibular condyle. Femoral distal condyles, are relative transverse breadth, fibular (including the epicondyle) much broader than tibial. Femoral distal condyles, articular surface shape, seem to be restricted to distal portion of femur.

Tibia: An almost complete slender right tibia (proximal narrow tibia MSM-72-2 and distal tibia MSM-186-2) (Figure 4) (Figure 7) with well preserved proximal and distal ends were found associated as partial skeleton like a pair of femora, tibiae, humeri and other bones (Figure 4) from lower Bor 2 (westernmost Bor 2). The lower Bor tibia is associated with humerus having anteriorly well exposed and well expanded radial condyle which is different than Isisaurus colberti. Further this tibia of Pakisaurus balochistani is different than the more robust and stocky tibiae (subcircular proximal tibia with equal/subequal anteroposterior and transverse widths) of Saraikimasoom vitakri, robust and stocky tibiae (convex lense shaped proximal tibia with more anteroposterior width than transverse width) of Gspsaurus pakistani, and flattened tibia (with more broad distal end) of Isisaurus colberti. Pakisaurus balochistani has transversely narrow and thin, flattened tibia with anteroposterior more broader distal end. This proximal tibia has fibular condyle and a prominent dorsolaterally longitudinal ridge started from the fibular condyle and extends down and terminated upto ventral end of cnemial crest. It generally forms arc shape concaving toward cnemial crest form- 
ing scar and convexing anteroventrally. Pakisaurus distal tibia proportion is relatively more broader (about $20 \mathrm{~cm}$ anteroposterior width) than the Zubra peak 7 distal tibia (16cm anteroposterior width) of Isisaurus while the proximal anteroposterior width are approximate same as about $25 \mathrm{~cm}$. The ratio of anteroposterior width of distal end $(20 \mathrm{~cm})$ to anteroposterior width of proximal end $(25$ $\mathrm{cm}$ ) of Pakisaurus balochistani is 0.80 while the ratio of anteroposterior width of distal end $(16 \mathrm{~cm})$ to anteroposterior width of proximal end $(25 \mathrm{~cm})$ of Isisaurus colberti tibia is low as 0.64 . The midshaft of Pakisaurus, Isisaurus and also Gspsaurus is elliptical and oval anteroposteriorly while the shaft of Saraikimasoom vitakri is subcircular to D-shaped. Proximally, the prominent cnemial crest projects anterolaterally or laterally and contacted with the anterior profile of the proximal fibula. The anterior part of fibular condyle or ridge is articulated with the posterior part of proximal fibula. However some part of cnemial crest is destroyed. The fibular condyle cone is tilted anterolaterally for the adjustment of fibula. The distal end of the tibia is anteroposteriorly broad like Isisaurus (but transversely broad in Gspsaurus and Saraikimasoom). The anteroventral ascending process and posteroventral descending process of Pakisaurus (and also Isisaurus) are relatively reduced than Gspsaurus and Saraikimasoom. The midshaft of the tibia is transversely compressed. The uncovered posterior half may be called as posterior process of proximal tibia is to equalize the anteroposterior width of distal femur and especially the anteroposteriorly broader tibial condyle. The second purpose may be enlargement of muscle attachment area to support the heavy weight femur and body weight. This support is improved by circular and subcircular proximal tibiae of gspsaurids which also have dorsally concave surface for the adjustment of tibial condyle and femur heavy load and body weight. The poorly preserved slender tibia K20/321 [35] from India did not provide detailed characters because of its poor preservation. The midshaft is oval and anteroposteriorly about thrice time than the transverse depth of Isisaurus, while in Pakisaurus it is more than 3 times, in Gspsaurus it is more than 2 times and in Saraikimasoom it is less than 1.5 times. At midshaft the tibia is not twisted in Pakisaurus and Isisaurus while it is twisted $90^{\circ}$ toward distal end in Gspsaurus and Saraikimasoom. The proximal head of the tibia is generally flattened with moderately expanded fibular condyle that projects laterally and cone is tilted anteriorly (Figure 4). Distal end of tibia is quite slender with reduced anterior and posteroventral processes. Tibial proximal condyle, shape, transversely thin and narrow, long axis anteroposterior; Tibial cnemial crest, orientation, projecting anteriorly and cnemial crest end to laterally; Tibia, distal breadth: more than twice midshaft breadth; Tibial distal posteroventral process, size, shortened transversely; Posterior fossa of astragalus visible posteriorly;

The Bruhathkayosaurus [71] was reported as carnosaur but these bones especially slender tibia may be referable to pakisaurid the slender and large sized titanosaurs. The Bruhathkayosaurus tibia is 2 meter long with proximal width 650 
$\mathrm{cm}$ and distal end width $600 \mathrm{~cm}$ and shaft is $380 \mathrm{~cm}$ [71]. The 2 meter long and transversely thin tibia of Bruhathkayosaurus [71] matches close proportion to the Pakisaurids (Isisaurus and Pakisaurus). Further the very largest 2 meter unusual long and transversely thin tibia of Bruhathkayosaurus [71] shows its affinity to Pakisaurus because of larger caudal vertebrae of Pakisaurus balochistani than Isisaurus colberti. The ratio of anteroposterior width of distal end $(600 \mathrm{~cm})$ to anteroposterior width of proximal end $(650 \mathrm{~cm})$ is 0.92 of tibia of Bruhathkayosaurus, this ratio is close to Pakisaurus and also suggests the unusual long tibia assignment to Pakisaurus. The distal end of tibia is about one and half (1.5) of mid shaft width in Isisaurus, while in Pakisaurus it is about twice, this ratio suggests assignment to Isisaurus (contrary to Pakisaurus). The behavior of lateral fibular articular ridge or condyle and its downward extension is not clear in figure of unusual $2 \mathrm{~m}$ long tibia. Conclusively its assignment to slender and large pakisaurids titanosaur is clear so far but its unusual large size shows affinity to Pakisaurid. The distal end of tibia of both Gspsaurus pakistani and Saraikimasoom vitakri have quite transversely broad proximal and distal ends (Figure 7) while Pakisaurus balochistani and Isisaurus colberti both have anteroposteriorly broad distal end of tibia (Figure 7).

Fibula: A pair of fibula (proximal right fibula MSM-349-4 and distal fibula MSM-580-4, Figure 2; proximal left fibula MSM-384-4, Figure 3) collected from south Kinwa, and a distal fibula MSM-183-2 found from lower Bor 2 (Figure 4). The proximal right fibula MSM-349-4 (Figure 2) and distal fibula MSM-183-2 (Figure 4) is well preserved and provides facility for description. The proximal fibula have rugosities on the proximal surface, while extending diagnostic parallel coarse or finger like rugosities oriented dorsoventrally in the lateral and also medial views (Figure 2). The fibular proximal tibial scar is also found. There is a ridge in the base of medial scar, starting from dorsoposterior corner trending obliquely anteroventrally. The distal fibula is subcircular to suboval shape (Figure 4). Fibular distal condyle size is expanded and not equal to mid shaft. The fibula K27/489 [35] from India assigned with Titanosaurus indicus materials show its assignment as Pakisaurus balochistani. Distal fibula laterally has a notch or keel type structure at the distal ends. Medially slight dorsoventrally elongated concavity is found. Fibula with inset anterior crest set off by ridge. Fibula, proximal tibial scar, seems to be well-marked and deepening anteriorly. The size of fibular distal condyle, expanded transversely, more than twice midshaft breadth.

Metatarsal: Partial metatarsal MSM-350-4 (Figure 2) was collected from south Kinwa. Metatarsal is relatively broad than metacarpal. It is elongated, triangular and has rugose articular surfaces. Metatarsal condyle shape is undivided. It has no central concavity.

Ungual fossil and fit in tracks from Pakistan, Mesozoic ichnotaxa: The ungual or claw MSM-152-3 is sickle-shaped, much deeper dorsoventrally than broad transversely (Figure 5). This Pakisaurus balochistani sickle shaped ungual 
is best fit with the track of latest Cretaceous track of titanosaurian sauropod Dgkhanpodus maarri [27]. This ungual is not fit with any tracks of latest Jurassic sauropods (or may be ornithischians) Malakhelpodus mianwali [11] [27] [72] and latest Cretaceous sauropods (or may be ornithischians) Pashtopodus zhobi [17] [27], latest Jurassic possible tracks of pterosaur [73] and latest Cretaceous possible tracks of pterosaur Anmolpodus alleni [27], latest Jurassic large theropod Samanapodus surghari [27] [72] and latest Jurassic small theropod Himalayapodus potwari [27] [74]. Here the names of footprint/ichnotaxa from the Mesozoic of Pakistan are being renamed according to ichnological name to avoid any misunderstanding with fossil bone taxa from Indo-Pakistan subcontinent. The Dgkhanpodus maarri renamed here from Dgkhansaurus maarri [27], Malakhelpodus mianwali renamed here after Malakhelisaurus mianwali [11] [27] [72], Pashtopodus zhobi renamed here after Pashtosaurus zhobi [17] [27], Samanapodus surghari renamed here after Samanadrinda surghari [11] [27] [72], and Himalayapodus potwari renamed here after Himalayadrinda potwari [27] [74], and Anmolpodus alleni renamed here after Anmolpakhi alleni [27] due to being ichnological name.

\section{Filling of Missing Gaps in Isisaurus colberti}

The Isisaurus colberti shares with Poripuchia because all the reported its caudal vertebrae especially distal caudals from India and Pakistan show procoely. The Isisaurus colberti shares with Pakisauridae (medium to large sized slender titanosaurs) the ratio of mid transverse width above and below of mid caudal centrum is about 1.00 i.e. the ventral view of mid caudal centra are not compressed or slightly compressed and slender flattened tibia with anteroposteriorly broad distal ends, while Gspsauridae is represented by ventrally reduced mid caudals and stocky tibia with transversely broad distal ends.

Isisaurus colberti is represented by one associated partial skeleton from India [25] and three associated partial skeletons from Pakistan. These three associated partial skeleton includes the holotypic caudal vertebrae of Sulaimanisaurus gingerichi [9] from south Kinwa 4; referred slender flattened tibia, fibula and metatarsal (Figure 6) of Sulaimanisaurus gingerichi from Zubra peak 7; and slender humerus and femur (Figure 6) of Sulaimanisaurus gingerichi from lower Sangiali 1 . It is necessary to mention that the Sulaimanisaurus gingerichi fossils are referred to Isisaurus colberti due to more similarity and recent recognition of 4 taxa of titanosaurs out of fifteen named titanosaurs from Indo-Pakistan subcontinent. So now these three associations from Pakistan are being referred to Isisaurus colberti which have filled many significant missing gaps (Figure 6) of Isisaurus colberti for the understanding of missing links and fuller anatomical features. Isisaurus colberti [25] have many missing bones especially cranial, hind limb and foot bones. Here the author referred some missing bones of hind limb and foot bones from Zubra Peak 7, and some overlapping distal humerus and distal femur bones from Sangiali 1, Pakistan (Figure 6). Isisaurus colberti has 


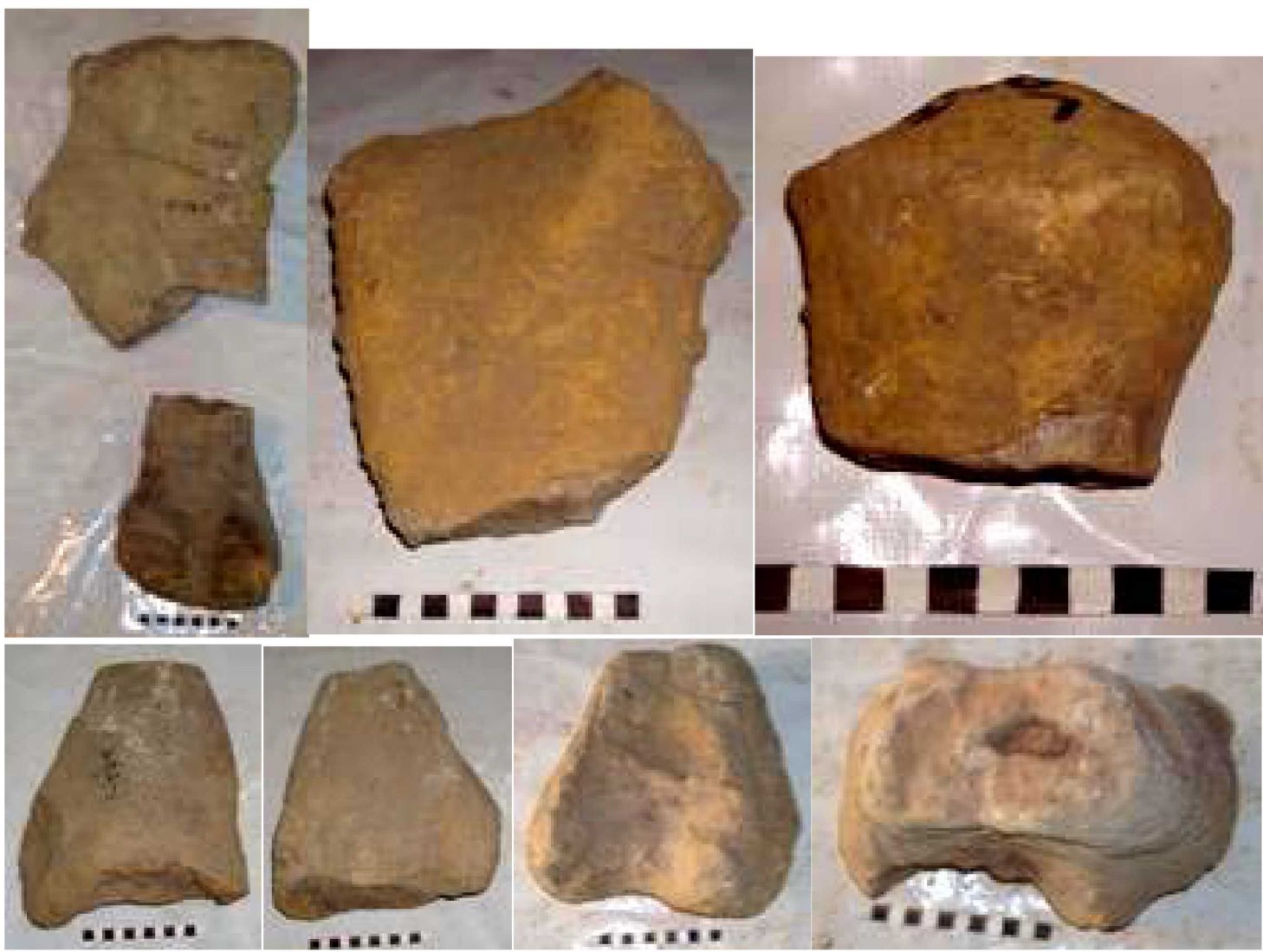

Figure 6. Isisaurus colberti some significant missing gaps filled here as referred materials from Pakistan (rows 1 and 2). From Pakistan this materials are the referred materials of Sulaimanisaurus gingerichi but here this materials are being referred to Isisaurus colberti due to recent recognition of four titanosaur taxa (Pakisaurus and Isisaurus pakisaurid slender Poripuchia titanosaurs; Gspsaurus and Saraikimasoom gspsaurid stocky Poripuchia titanosaurs) from Indo-Pakistan subcontinent. Row 1, p1, flattened and transversely compressed right tibia MSM-235-7 with anteroposteriorly broad distal tibia; p2, proximal right fibula MSM-253-7; p3, right metatarsal MSM-296-7. Row 2, p1, 2, right distal humerus MSM-262-1 in anterior and posterior views; p3, 4, right distal femur MSM-232-1 in posterior and cross sectional view. Scale each black or white digit is $1 \mathrm{~cm}$. Note, at places Kinwa or south Kinwa locality number is represented by 4 or 4 s, mid Kinwa locality number is represented by $4 \mathrm{~m}$, and north Kinwa locality number is represented by $4 \mathrm{n}$.

flattened or transversely thin proximal tibia with relatively less anteroposteriorly broad triangular distal view of distal ends (Figure 6) than Pakisaurus balochistani (Figure 7) which have broader distal end. The anteroposteriorly width of tibial shaft is about 3 times the transverse width, while in Gspsaurus it is more than 2 times and in Saraikimasoom it is subcircular or less than 1.5 times. The diagnostic taxon Isisaurus colberti have flattened tibia. The outer morphology, proportional measurement, shape and features allow its identification and assignment to Isisaurus colberti because its proportion of distal tibia is relatively less (16 cm anteroposterior width) than the lower Bor distal tibia (about $20 \mathrm{~cm}$ anteroposterior width) of Pakisaurus while the proximal anteroposterior width are approximately same as $25 \mathrm{~cm}$. It is likely that both may have about $80-100$ $\mathrm{cm}$ length. It is also necessary to mention that the anteroposterior breadth of proximal tibiae are almost same in all main describing tibia but its transverse 
width is variable and allow their distinction with other characters among each others (Figure 7). Its ratio of anteroposterior width of distal end $(16 \mathrm{~cm})$ to anteroposterior width of proximal end $(25 \mathrm{~cm})$ is 0.64 while the ratio of Pakisaurus tibia is high as 0.80 .

The distal humerus (Figure 6) has no expanded and anteriorly exposed radial condyle like its holotypic humerus, and unlike other poripuch titanosaurs from Indo-Pakistan. The right femur has same size as the distal humerus and both found from same site of lower Sangiali 1, so believed associated.

The distal femur (Figure 6) is slender and has triangular shaped small hollow cavity observed in the cross sectional view.

Fibula (Figure 6) has medial crest trending dorsoposteriorly to anteroventrally and terminating at mid way. Further this fibula has no rugose parallel structures (Figure 6) unlike the fibula of Pakisaurus balochistani (Figure 3). Metatarsal is thick subcircular shaft and convex shaped end.

\section{Recognized four Titanosaur Taxa from Indo-Pakistan Subcontinent; Their Typical Key Elements and Comparison}

The recent [20] [21] [22] [23] [24] [27] and present work recognized four titanosaur taxa out of the total 15 named taxa of titanosaurs from Indo-Pakistan. These recognized four taxa from South Asia are Pakisaurus balochistani and Isisaurus colberti pakisaurid Poripuch slender titanosaurs, and Gspsaurus pakistani and Saraikimasoom vitakri gspsaurid Poripuch stocky titanosaurs. Further this assessment is consistent with the clues of four taxa of titanosaur from Madagascar.

Most of the workers recognized three or four titanosaur taxa from Indo-Pakistan [1] [20] [21] [22] [23] [24] [27] [35] [75]. The fossils reported by [35] show three titanosaurs while fourth titanosaur Isisaurus colberti was reported later in 1997 [25]. Reference [16] recognized two titanosaur taxa from Indo-Pakistan. The present work and other recent discoveries [21] [23] from Pakistan since 2000 to so far revealed at least four titanosaurs with four diverse cranial and postcranial fossils like skull and teeth, tibiae, humeri, femora, scapulae, caudal vertebrae and others. The major problem in considering only two titanosaur taxa is the referring of tetra diverse and diagnostic fossils collected from India and Pakistan so far. While this problem is solved, when [20] [21] [22] [23] [24] and present work revealed four recognized titanosaur taxa from Indo-Pakistan on diagnostic tetra diverse associated cranial and postcranial skeletons especially tibiae. Their typical key elements and comparison are being presented here.

Four typical key tibiae of Poripuch titanosaurs from Indo-Pakistan: Two types of slender, flattened, transversely compressed tibia (described above), and two types of stocky and transversely expanded tibia described by [21] [23] along with other bones resolved certainly the long standing controversy regarding the number of taxa of titanosaurs from Indo-Pakistan. Now it became certain by four types of tibia (Figure 7) along with other associated cranial and postcranial 


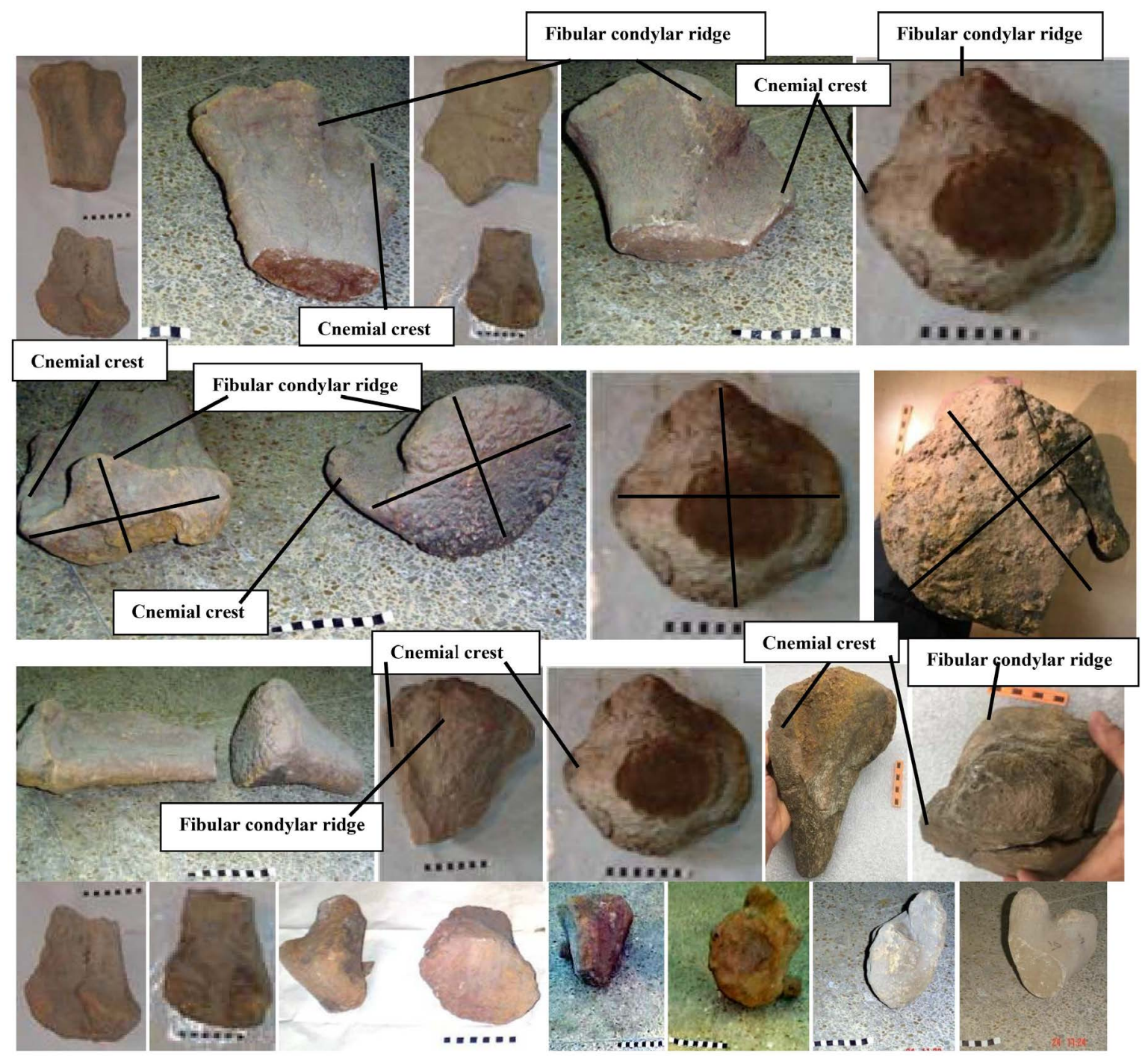

Figure 7. Four types of key tibiae of four recognized titanosaur taxa found from Pakistan and their comparison. Row 1, p1, 2, first quite slender tibia, transversely compressed and flattened proximal right tibia MSM-72-2 with quite broad distal end MSM-186-2 of Pakisaurus from lower Bor; p3, second slender tibia, transversely compressed and flattened proximal right tibia with broad distal end MSM-235-7 of Isisaurus from Zubra peak; p4, third robust/stocky tibia, transversely expanded biconvex lense shaped proximal right tibia MSM-73-16 of Gspsaurus from Top Kinwa; and $\mathrm{p} 5$, fourth quite robust tibia, proximal right tibia with subsquare proximal left tibia MSM-246-15 with equal transverse and anteroposterior widths of Saraikimasoom found from Mari Bohri. Row 2, p1, comparison of right tibiae MSM-72-2 and MSM-73-16 of Pakisaurus and Gspsaurus respectively; p2, 3, subsquare proximal left tibiae MSM-246-15 and GSP/Sangiali-1120 of Saraikimasoom from Mari Bohri and mid-Sangiali. Row 3, p1, comparison of right tibiae MSM-72-2 and MSM-73-16 of Pakisaurus and Gspsaurus respectively; p2, 3, 4, 5, quite robust subsquare proximal left tibiae MSM-246-15 and GSP/Sangiali-1120 of Saraikimasoom in lateral and ventral views. Row 4, p1, anteroposteriorly quite broad right distal tibia MSM-186-2 of Pakisaurus; $\mathrm{p} 2$, anteroposteriorly broad right distal tibia MSM-235-7 of Isisaurus; p3, transversely broad subrectangular left distal tibia MSM-569-19 and right distal tibia MSM-710-19 of Gspsaurus from Alam; p4, 5, transversely broad subrectangular right distal tibia MSM-710-19 in mediodorsal and ventral views of Gspsaurus from Alam; p6, 7, transversely broad subrectangular (suboval) right distal tibia MSM-75-9 of Saraikimasoom found from Grut in ventral and laterodorsal views. Scale, each black digit is $1 \mathrm{~cm}$.

materials. The outer morphology, proportional measurement, shape and features of tibiae of recognized four taxa allow its distinction. Saraikimasoom has quite 
robust and stockiest (most expanded transversely and anteroposteriorly approaches their equal widths), proximal tibia with equal anteroposterior and transverse width (subsquare shaped femoral articular surface in proximal view) with subsquare to subcircular shaped mid shaft cross section (anteroposteriorly width of shaft may be about same or slightly more than transverse width), and quite robust transversely broad suboval to subrectangle shaped distal tibia (Figure 7), Gspsaurus has robust and stocky (expanded anteriorly and transversely), proximal tibia (anteroposteriorly slightly long, asymmetric biconvex lense shaped femoral articular surface in proximal view) with oval shaped mid shaft cross section (anteroposteriorly width of shaft may be about or slightly more than twice transverse width), and quite robust transversely broad subrectangle shaped distal view of distal tibia (Figure 7), Isisaurus colberti has slender transversely compressed proximal tibia, with anteroposteriorly broad triangle shaped distal view of distal tibia (Figure 7), and Pakisaurus has quite slender flattened and transversely compressed proximal tibia with anteroposteriorly quite broad/more broader distal tibia than Isisaurus colberti (Figure 7).

Jainosaurus (=Antarctosaurus) septentrionalis is based on braincase, vertebra and left and right scapula two left humeri and one or two weathered bones reported from Bara Simla India [35] which represents dual affinity and chimera nature, and further also no associated other materials. Two braincases are reported from Pakistan [21] [23] and four braincases from India [76]. Pakistani braincases have constricted sagital groove and $\mathrm{w}$-shaped occipital condyle and all Indian braincases have $\mathrm{D}$-shaped condyles with no sagital groove, while as a whole all six are different. This braincase GSI K27/497 of Jainosaurus (=Antarctosaurus) septentrionalis [35] referred to Pakisaurus balochistani [24] due to large size with D-shaped condyle and distinguished from $\mathrm{W}$-shaped condyle of braincases of Gspsaurus [20] [21] and Saraikimasoom [22] [23], and D-shaped small sized braincase of Isisaurus colberti. The scapula has affinity to Isisaurus colberti due to relatively longer articular surface for coracoids, while this articular surface is relatively shorter in the Pakisaurus, Saraikimasoom and Gspsaurus. Pakisaurus has transversely relatively less expanded distal scapula, Saraikimasoom has transversely relatively expanded distal scapula, and Gspsaurus has transversely relatively more expanded distal scapula. Further the two humeri of Jainosaurus (=Antarctosaurus) septentrionalis [35] are also different with each other and may belong to two different taxa. The vertebra of Jainosaurus (=Antarctosaurus) septentrionalis [35] may be referable to Pakisaurus. The Chota Simla assemblages of Matley [32] were referred to Jainosaurus (=Antarctosaurus) septentrionalis [16]. Again the materials described by [16] have dual affinity. The vertebra described by [16] is referable to Pakisaurus due to tall, flat sided and ventrally not reduced. The associated limb elements described by [16] referable to Gspsaurus [21] due to transversely expanded and anteroposteriorly long lense shaped typical key tibia.

Diverse femora of Poripuch titanosaurs from Indo-Pakistan: Four types of 
femora of four recognized taxa of titanosaurian sauropods are reported from Indo-Pakistan. Their comparisons can be explained as below. The Saraikimasoom vitakri [23] and Gspsaurus pakistani [21] femora are relatively more expanded anteroposteriorly than the Pakisaurus balochistani and Isisaurus colberti femora. The Pakisaurus balochistani shows (wavy style) rounded proximal one third deflection and then became vertical straight just close to greater trochanter while Saraikimasoom have medially deflection with straight line lateral profile from deflection point to greater trochanter. The Saraikimasoom vitakri and Gspsaurus pakistani show mid shaft transverse width 2 times than anteroposterior thickness while the Pakisaurus balochistani and Isisaurus colberti have 3 times mid shaft transverse width than anteroposterior thickness. The Saraikimasoom vitakri and Gspsaurus pakistani show relatively more expanding anteroposteriorly tibial and fibular condyles than Pakisaurus balochistani and Isisaurus colberti. The Saraikimasoom vitakri and Gspsaurus pakistani have rugosities on the distal femur which extended on to shaft while Pakisaurus balochista$n i$ and Isisaurus colberti show no rugosities extension.

Diverse humeri of Poripuch titanosaurs from Indo-Pakistan: The diverse morphologies of humeri were recorded for four recognized taxa of titanosaurian sauropods from Indo-Pakistan. First morphology of humerus [25] is large and transversely more expanded belongs to Isisaurus colberti, which represents humerus without expanded radial distal condyle which is not expanded well anteriorly. Second morphology of humerus (presented here) is also large and transversely expanded belongs to Pakisaurus balochistani, which represents distal condyle expanded or well divided especially radial condyle is expanded and exposed anteriorly and situated almost at the transverse centre. Third morphology of humerus [21] is moderate in size belongs to Gspsaurus pakistani, which represents prominent medial process of medial limb of proximal humerus is more extruded in the medial side (with possibly distal condyle expanded or well divided). Fourth morphology of humerus [23] is relatively small belongs to Saraikimasoom vitakri which represents distal humerus with expanded radial condyle exposed anteriorly but situated offset from centre. The deltopectoral crest is shifted medially shown in the Sangiali humeri of Saraikimasoom Vitakri and also like the Chota Simla humerus of Gspsaurus pakistani.

Five types of caudal vertebrae of titanosaurs from Indo-Pakistan: Five types of vertebrae especially caudal vertebrae [9] of poripuch titanosaurs were diagnosed from Indo-Pakistan subcontinent. First type, tall mid caudals with ratio of mid transverse width above and below of centrum is about 1 belong to $P a-$ kisaurus balochistani; slightly tall mid caudals with ratio of mid transverse width above and below of centrum is about 1.3 to 1.5, belong to Gspsaurus pakistani; squarish to broad mid caudals with ratio of mid transverse width above and below of centrum is about 1.5 to 2, belong to Saraikimasoom vitakri; squarish mid caudal with ratio of mid transverse width above and below of centrum is about 1, belong to Isisaurus colberti or Sulaimanisaurus gingerichi; squarish mid caud- 
al with ratio of mid transverse width above and below of centrum is slightly less than 1, belong to Khetranisaurus barkhani.

Diverse skulls of titanosaurs from Indo-Pakistan: Four braincases were described from the latest Maastrichtian Vitakri Lameta Formation in Bara Simla and Dongargaon localities of central India and Rahioli locality of western India [76]. Two braincases reported from the latest Maastrichtian Vitakri Lameta Formation in Alam [21] and Eastern Top Kinwa [23] localities of Balochistan, central Pakistan. The Kinwa locality braincase assigned to Saraikimasoom vitakri and Alam locality braincase is part of holotype of Gspsaurus pakistani. All these braincases are different from each other. In this way more than four types of braincases were reported from Indo-Pakistan like large braincase having thick quadrangular occipital condyle with median cut, ventral W-shaped surface and dorsal reverse W-Shaped surface and almost straight lateral sides of Gspsaurus pakistani [21]; relatively small braincase with convex lateral sides and ventral feeble W-shaped of Saraikimasoom vitakri [23]; large braincase with D-shaped and convex lateral sides of Pakisaurus balochistani; and small braincase with D-shaped and lateral convex sides belong to Isisaurus colberti.

Three or four types of snout/rostrum (skulls) were reported from Indo-Pakistan. First type of small skull of Gspsaurus pakistani having V shaped mandible teeth row with circular to subcircular, long slender, recurved and conical teeth particularly characterised by decreasing teeth diameter from base to tip [20] [21]. Second type of very small skull of Saraikimasoom vitakri having U shaped mandible teeth row with circular to subcircular, long slender, recurved and conical teeth particularly characterised by decreasing teeth diameter from base to tip [22] [23]. Third type of Pakisaurus balochistani circular to subcircular, long slender and recurved teeth with constant tooth diameter from base to tip (except tip) similar to teeth and may be similar to the skull of Rapetosaurus [27]. The fourth type of skull may belong to Isisaurus colberti.

\section{Associations and Partial Skeletons of Poripuchian Titanosaurs from the Latest Cretaceous Vitakri and Lameta Formations of Indo-Pakistan Subcontinent (South Asia)}

The Cretaceous dinosaur fauna of Indo-Pakistan has remained poorly understood because of a lack of associated and articulated remains, proliferation of named species, and an incomplete understanding of the clades present [16]. Due to recent discoveries from Pakistan, the above problems are resolved. The recent work [20] [21] [22] [23] [24] [27] and present work recognized four titanosaur taxa out of the total 15 named taxa of titanosaurs from Indo-Pakistan. Recognized four taxa from South Asia are Pakisaurus balochistani and Isisaurus colberti pakisaurid Poripuch slender titanosaurs, and Gspsaurus pakistani and Saraikimasoom vitakri gspsaurid Poripuch stocky titanosaurs. These recognized four taxa of titanosaurs based on the following associated partial skeletons. These 
associated skeletons provide a fuller understanding of its anatomy and phylogenetic affinities.

Pakisaurus balochistani is represented by two associated partial skeletons from Pakistan like the holotypic vertebral and appendicular elements [77] (Figures 1-3) from Kinwa (the western site of South Kinwa) and its exemplar associated skeleton of vertebral and mostly appendicular elements (Figure 4) from lower Bor 2 locality. The Pakisaurus balochistani holotypic associated partial skeleton of south Kinwa includes the cervical, cervicodorsal, dorsal, sacral and caudal vertebrae, sternal, a pair of scapula (left and right scapula), right humerus, radius, a pair of ulna (left and right ulna), ilium, right femur, a pair of fibula (left and right fibula), manus/pes foot bones (Figures 1-3).

The other associated partial skeleton of Pakisaurus balochistani found from lower Bor 2 includes the caudal vertebrae, sternal, a pair of scapula (left and right scapula), right humerus, radius, a pair of ulna (left and right ulna), ilium, right femur, a pair of fibula (left and right fibula), and manus/pes foot bones (Figure 4). Here the slender flattened tibia (Figure 4, Figure 7) is the major typical key element for the diagnosis of Pakisaurus balochistani. The four typical key tibiae are found from Pakistan which shows affinity to four recognized titanosaur taxa from Indo-Pakistan. Besides these two associated partial skeletons, many bones are being referred to Pakisaurus balochistani from Pakistan (Figure 5) and India.

Isisaurus colberti is represented by one associated partial skeleton from India [25] and three associated partial skeletons from Pakistan (added here). Three associated partial skeleton includes the holotypic caudal vertebrae of Sulaimanisaurus gingerichi [9] from south Kinwa 4, slender flattened tibia, fibula and metatarsal (Figure 6) (Figure 7) of Sulaimanisaurus gingerichi from Zubra peak 7 and slender humerus and femur (Figure 6) of Sulaimanisaurus gingerichi from lower Sangiali 1. It is necessary to mention that the Sulaimanisaurus gingerichi fossils are referred to Isisaurus colberti due to recent recognition of 4 taxa of titanosaurs out of fifteen named titanosaurs from Indo-Pakistan subcontinent. So now these three associations from Pakistan are being referred to Isisaurus colberti which have filled many missing gaps (Figure 6) of Isisaurus colberti for the understanding of fuller anatomical features.

Gspsaurus pakistani is represented by three associated partial skeletons from Pakistan and one associated partial skeleton from India [21]. First the Gspsaurus pakistani holotypic cranial, vertebral and appendicular skeleton from central Alam 19 which includes the partial skull with braincase, cervical, dorsal and caudal vertebrae, partial ilium or sternal, a pair of scapula (left and right scapula), radius, left femur, and a pair of tibia (left and right tibia). Second the associated partial skeleton of Gspsaurus pakistani found from Top Kinwa 16 locality includes the dorsal, sacral and caudal vertebrae, sternal, a pair of scapula (left and right scapula), radius, a pair of ulna (left and right ulna), ilia, left tibia fibula and a pair of fibula (left and right fibula). Third the associated partial skeleton of 
Gspsaurus pakistani found from Mari Bohri 15 locality includes the first biconvex caudal and other procoelous caudal vertebrae, right scapula, right pubis and right femur. The fourth associated partial skeleton of Gspsaurus pakistani reported from Chota Simla India by [16] [32] includes a pair of humeri (left and right humerus), left radius, left femur, left tibia and left fibula. Besides these four associated partial skeletons, many bones are being referred to Pakisaurus balochistani from Pakistan and India.

Saraikimasoom vitakri is represented by four associated partial skeletons from Pakistan [23]. First the Saraikimasoom vitakri holotypic snout including the articulated lower and upper jaw bones with full teeth rows and some other skull bones from South Kinwa 4. Second the associated partial skeleton of Saraikimasoom vitakri found from north Kinwa 4 n locality includes jaw bone with 6 complete teeth, cervical, dorsal and caudal vertebrae, humerus, radius, pubis, a pair of femur (left and right femur) and a pair of tibia (left and right tibia). Third the associated partial skeleton of Saraikimasoom vitakri found from Mari Bohri 15 locality includes the cervical, dorsal, first biconvex caudal and other procoelous caudal vertebrae, left sternal, left humerus, left ulna, left acetabulum, left femur and left tibia. Fourth possible associated partial skeleton of Saraikimasoom vitakri found from mid Sangiali 1 locality includes the cervical, cervicodorsal, dorsal and caudal vertebrae, left scapula, left humerus, left coracoid, left and right femur, left tibia and left fibula, while this site also produced two more proximal humerus and one more cervicodorsal vertebra revealing three animals of Saraikimasoom vitakri at mid Sangiali 1. Besides these four associated partial skeletons, many bones referred to Saraikimasoom vitakri from Pakistan and India.

Further theropods [78] [79], mesoeucrocodiles [78] [80] [81], and pterosaurs [27] [78] were also were also found from the latest Cretaceous (67 - 66 Million years ago/Mya) Vitakri Formation [4] [15] [16] of Fort Munro Group [16] from Pakistan. First large sized theropod Vitakridrinda sulaimani is represented by holotypic skeleton [78] includes more than 10 teeth and a few cranial small bones, tall dorsal vertebra and a pair of femora (left and right femur) from Alam 19 type locality [78], and referred materials include possibly partial skeleton of tall dorsal vertebrae, subcircular caudal vertebra, whiplash elongated distal caudal centrum and metatarsals from Top Kinwa 16 [78], tall dorsal vertebra from Sangiali 1 [78], and anterior caudal vertebrae from Mari Bohri 15 [78]. Second large sized theropod Vitakrisaurus saraiki [79] is represented by holotypic skeleton [78] includes almost complete manus with articulated and associated its most of the elements, anterior and mid caudal vertebrae, proximal ulna, cross section of humerus and limb bones found from mid-Bor 2 type locality [78], and referred materials include subcircular cylindrical dorsal vertebra from Shalghara 3 locality of Vitakri dome area, Barkhan district, possibly leg bones [78] from Karkh area of Khuzdar district, Pakistan, and a caudal vertebra with two chevrons [35] [37] [78] from Bara Simla India. Medium to large sized mesoeucrocodile Induszalim bala [80] is represented by holotypic skeleton [78] includes snout/rostrum, 
rib, caudal vertebrae, proximal humerus and proximal ulna, metacarpals, ilium, femur, tibia articulated with fibula, and metatarsals found from mid Bor 2 type locality and referred materials include anterior snout with teeth, dentary ramus with 4 alveoli with partial teeth, jaw ramus with two teeth sandwiched by a diastema, anterior snout with articulated 2 teeth (one tooth on right and one on left jaw ramus) found from Shalghara 3, and dentary ramus with articulated four spaced teeth from Bor 2, and dorsal vertebra from Top Kinwa 16, Barkhan district, Balochistan and a partial rib/phalanges from south western vicinity of Khuzdar town, Balochistan. Medium to large sized mesoeucrocodile Pabwehshi pakistanensis [81] is represented by holotypic snout articulated with dentary found from Top Kinwa 16 and referred dentary symphysis from Shalghara 3. Medium to large sized mesoeucrocodile Sulaimanisuchus kinwai [82] is represented by holotypic dentary symphysis with articulated teeth and proximal humerus from south Kinwa 4 or 4 s. Medium to large sized pterosaur Saraikisaurus minhui [78] is represented by holotypic beak or dentary with articulated 8 teeth (some teeth are overlapped) found from Top Kinwa 16, Barkhan District, Pakistan [78] and referred jaw with overlapped teeth [83] from Kotah, Rajasthan, India [78]. Further recently discovered basilosaurid, baluchithere rhinoceros, horses, sea cow, proboscidean, eucrocodile, pterosaurs, plesiosaur, fishes, invertebrates and wood fossils, and footprints and trackways were reported from Pakistan [27]. All these fossils from Pakistan and their significant localities are geoheritage and paleobioheritage and assets of Pakistan which needs their protection [84] [85] [86] [87] and also considered significant remains from Pakistan which have no parallel from India [88]. These latest Cretaceous materials of titanosaurs [20] [21] [22] [23] [24] and present work, theropods [78] [79], Mesoeucrodiles [78] [80] and pterosaurs [27] [78] revealed paleobiogeographic Gondwanan affinity.

\section{Conclusions}

Due to lack of associated skeletons of slender and large titanosaurs from Indo-Pakistan (South Asia), this finding of holotypic associated skeleton from south Kinwa and referred associated skeleton from lower Bor, Balochistan, Pakistan is providing significant features of Pakisaurus balochistani a slender and large titanosaur from Indo-Pakistan subcontinent. There is also lack of cranial and associated postcranial remains of titanosaurs in Indo-Pakistan but this cranial, and associated postcranial remains of Pakisaurus balochistani slender and large titanosaur from Indo-Pakistan provides significant and distinct cranial and postcranial features for the comparison, evolutionary and phylogenetic studies of titanosaurs in the globe.

Isisaurus colberti which is based on associated postcranial skeletons has many important missing links. Among these some significant missing links especially hind limb elements, are partly filled and added here. This filling of missing gaps of Isisaurus colberti the slender titanosaur from Pakistan is unique gift and pro- 
vided the key elements especially slender flattened and transversely compressed tibia with key features for future phylogenetic studies.

So far no any comparison of Indo-Pakistan titanosaur fauna is made but here a comparison of cranial, vertebral, appendicular and limb elements of four recognized taxa of titanosaurs from Indo-Pakistan is presented. Recently the four recognized titanosaur taxa from Indo-Pakistan include the two slender titanosaurs like Pakisaurus and Isisaurus and two stocky titanosaurs like Gspsaurus and Saraikimasoom.

Fortunately the four typical key tibiae of four recognized titanosaur taxa associated with other elements were found from Pakistan. There was a long standing controversy and issue regarding the valid and coexisting titanosaur taxa in Indo-Pakistan subcontinent. Luckily the findings of four typical key tibiae (along with associated cranial and postcranial skeletons) discarded the hypothesis of two titanosaur taxa from Indo-Pakistan subcontinent and revealed two distinct slender poripuchian titanosaurs and two distinct stocky poripuchian titanosaurs from Indo-Pakistan subcontinent.

The extension of procoely into anterior and middle caudal vertebrae has been considered a feature of lithostrotian [51] [52] [53] [54] [55], while the extension of procoely into anterior and middle and posterior caudal vertebrae from Indo-Pakistan subcontinent has been considered a feature of Poripuchia [4] [27] titanosaurs. Poripuch is the Saraiki language word means full tail (with procoelous vertebrae). The Poripuchia titanosaurs consist of all procoelous caudals including the distal caudals also; however in some taxa especially stocky titanosaurs the first caudal is biconvex. In pakisaurids and gspsaurids all the caudal vertebrae found so far belong to anterior, middle and distal caudal vertebrae are procoelous (except first biconvex caudal). The Poripuchia is the most inclusive clade containing all caudal procoelous (except first biconvex caudal in few taxa). The Poripuchia is the most inclusive clade containing Pakisaurus and Isisaurus of pakisaurids, and Gspsaurus and Saraikimasoom of gspsaurids the derived titanosaurs.

Further many cranial and postcranial associations of recognized two slender and two stocky titanosaurs from Pakistan and also India are presented and discussed. Pakisaurus balochistani slender titanosaur has two associations from south Kinwa and lower Bor in Pakistan, while Isisaurus colberti slender titanosaur has one holotypic association from Dangargaon India and three brief associations from Pakistan, which is the holotypic and exemplars of Sulaimanisaurus gingerichi, here being referred to Isisaurus colberti. Besides slender titanosaurs, the stocky titanosaurs are relatively more common in Pakistan and also have more associations of cranial and postcranial skeletons. Gspsaurus pakistani have three association from Pakistan like Alam, Top Kinwa, Mari Bohri and mid Bor of Pakistan and one association from the Chota (Chhota) Simla of India. Saraikimasoom vitakri have one holotypic snout (including articulated lower and upper jaws and complete teeth row) found from south Kinwa, and other three 
associations from Pakistan like north Kinwa, Mari Bohri, mid Sangiali (probably), south Zubra Basti Nala and Grut localities of Pakistan.

\section{Conflicts of Interest}

The author declares no conflicts of interest regarding the publication of this paper.

\section{References}

[1] Sahni, A. (2001) Dinosaurs of India. National Book Trust, Delhi, 110.

[2] Malkani, M.S. and Anwar, C.M. (2000) Discovery of First Dinosaur Fossil in Pakistan, Barkhan District, Balochistan. Geological Survey of Pakistan Information Release, 732, 1-16

[3] Malkani, M.S. (2006) Lithofacies and Lateral Extension of Latest Cretaceous Dinosaur Beds from Sulaiman Foldbelt, Pakistan. Sindh University Research Journal (Science Series), 38, 1-32.

[4] Malkani, M.S. (2019) Cretaceous Stratigraphy of Pakistan. Open Journal of Geology, 9, 671-673. https://doi.org/10.4236/ojg.2019.910071

[5] Malkani, M.S. (2003) Discovery of Partial Skull and Dentary of Titanosauria (Sauropod Dinosaur) from the Late Cretaceous Pab Formation of Vitakri Area, Barkhan District, Balochistan, Pakistan. Journal of Himalayan Earth Sciences, 36, 65-71.

[6] Malkani, M.S. (2003) Pakistani Titanosauria; Are Armoured Dinosaurs? Journal of Himalayan Earth Sciences, 36, 85-91.

[7] Malkani, M.S. (2003) First Jurassic Dinosaur Fossils Found from Kirthar Range, Khuzdar District, Balochistan, Pakistan. Journal of Himalayan Earth Sciences, 36, 73-83.

[8] Malkani, M.S. (2004) Saurischian Dinosaurs from Late Cretaceous of Pakistan. In: Hussain, S.S. and Akbar, H.D., Eds., Proceedings of Fifth Pakistan Geological Congress, National Geological Society of Pakistan, Pakistan Museum of Natural History, Islamabad, 14-15 April 2004, 71-73.

[9] Malkani, M.S. (2006) Biodiversity of Saurischian Dinosaurs from the Latest Cretaceous Park of Pakistan. Journal of Applied and Emerging Sciences, 1, 108-140.

[10] Malkani, M.S. (2006) Cervicodorsal, Dorsal and Sacral Vertebrae of Titanosauria (Sauropod Dinosaurs) Discovered from the Latest Cretaceous Dinosaur Beds/Vitakri Member of Pab Formation, Sulaiman Foldbelt, Pakistan. Journal of Applied and Emerging Sciences, 1, 188-196.

[11] Malkani, M.S. (2008) Marisaurus (Balochisauridae, Titanosauria) Remains from the Latest Cretaceous of Pakistan. Sindh University Research Journal (Science Series), 40, 55-78.

[12] Malkani, M.S. (2008) First Articulated Atlas-Axis Complex of Titanosauria (Sauropoda, Dinosauria) Uncovered from the Latest Cretaceous Vitakri Member (Dinosaur Beds) of Upper Pab Formation, Kinwa Locality of Sulaiman Basin, Pakistan. Sindh University Research Journal (Science Series), 40, 55-70.

[13] Malkani, M.S. (2010) Osteoderms of Pakisauridae and Balochisauridae (Titanosauria, Sauropoda, Dinosauria) in Pakistan. Journal of Earth Science, 21, 198-203. https://doi.org/10.1007/s12583-010-0212-Z

[14] Malkani, M.S. (2009) New Balochisaurus (Balochisauridae, Titanosauria, Sauropoda) and Vitakridrinda (Theropoda) Remains from Pakistan. Sindh University Re 
search Journal (Science Series), 41, 65-92.

[15] Malkani, M.S. (2010) New Pakisaurus (Pakisauridae, Titanosauria, Sauropoda) Remains and Cretaceous Tertiary (K-T) Boundary from Pakistan. Sindh University Research Journal (Science Series), 42, 39-64.

[16] Wilson, J.A., Barrett, P.M. and Carrano, M.T. (2011) An Associated Partial Skeleton of Jainosaurus cf. septentrionalis (Dinosauria: Sauropoda) from the Late Cretaceous of Chhota Simla, Central India. Palaeontology, 54, 981-998. https://doi.org/10.1111/j.1475-4983.2011.01087.x

[17] Malkani, M.S. (2014) Titanosaurian Sauropod Dinosaurs from the Latest Cretaceous of Pakistan. Abstract Volume of 2 nd symposium of IGCP 608 "Cretaceous Ecosystem of Asia and Pacific", Tokyo, Japan, 4-6 September, 108-111.

[18] Malkani, M.S. (2015) Dinosaurs, Mesoeucrocodiles, Pterosaurs, New Fauna and Flora from Pakistan. Geological Survey of Pakistan, Information Release, 823, 1-32.

[19] Malkani, M.S. (2015) Titanosaurian Sauropod Dinosaurs from Pakistan. In: Zhang, Y., Wu, S.Z. and Sun, G. Eds., Abstract Volume, 12 th Symposium on "Mesozoic Terrestrial Ecosystems (MTE 12), and 3rd Symposium of International Geoscience Program (IGCP 608) "Cretaceous Ecosystem of Asia and Pacific", Paleontological Museum of Liaoning/Shenyang Normal University, Shenyang, China, 15-20 August, 2015, 93-98.

[20] Malkani, M.S. (2019) Medium Sized Stocky Titanosaur from South Asia. Open Journal of Geology, 9, 631-634. https://doi.org/10.4236/ojg.2019.910060

[21] Malkani, M.S. (2020) First Skull of Medium Sized Titanosaur from Indo-Pakistan Subcontinent Found from Found from the Latest Maastrichtian Vitakri Formation of Pakistan; Associated Cranial and Postcranial Skeletons of Gspsaurus pakistani (Poripuchia, Stocky Titanosauria, Sauropoda) from Pakistan and India. Open Journal of Geology, 10, (In Press). https://doi.org/10.4236/ojg.2019.910059

[22] Malkani, M.S. (2019) Smallest Titanosaur from Indo-Pakistan Landmass. Open Journal of Geology, 9, 627-630. https://doi.org/10.4236/ojg.2019.910059

[23] Malkani, M.S. (2020) First Snout with Complete Teeth Row of Titanosaur from Indo-Pakistan Subcontinent Found from the Latest Maastrichtian Vitakri Formation of Pakistan; Associated Cranial and Postcranial Skeletons of Saraikimasoom vitakri (Poripuchia, Stocky Titanosauria, Sauropoda) from Pakistan and Referred Fossils from India. Open Journal of Geology, 10, (In Press).

[24] Malkani, M.S. (2019) Large Titanosaur from Indo-Pakistan Peninsula. Open Journal of Geology, 9, 635-638. https://doi.org/10.4236/ojg.2019.910061

[25] Jain, S.L. and Bandyopadhyay, S. (1997) New Titanosaurid (Dinosauria: Sauropoda) from the Late Cretaceous of Central India. Journal of Vertebrate Paleontology, 17, 114-136. https://doi.org/10.1080/02724634.1997.10010958

[26] Malkani, M.S., Islam, N., Mahmood, Z. and Rajper, R.H. (2017) New Celestite Deposits from Laki Shale and Limestone, and Some Evidences of Dinosaurs and Associated Vertebrates from Laki Anticline, Sindh Province, Pakistan. Geological Survey of Pakistan, Information Release, 1017, 1-18.

[27] Malkani, M.S. (2019) Recently Discovered Basilosaurid, Baluchithere Rhinoceros, Horses, Sea Cow, Proboscidean, Eucrocodile, Pterosaurs, Plesiosaur, Fishes, Invertebrates and Wood Fossils, Tracks and Trackways of Dinosaurs from Pakistan; Comparison of Recognized Four Titanosaur Taxa of Indo-Pakistan with Madagascar. Open Journal of Geology, 9, 919-955. https://doi.org/10.4236/ojg.2019.912098

[28] Owen, R. (1842) Report on British Fossil Reptiles, Pt. II. Reptiles. Report of the 
British Association for the Advancement of Science, No. 1841, 60-204.

[29] Seeley, H.G. (1888) The Classification of the Dinosauria. Report of the British Association for the Advancement of Science, No. 1887, 698-699. https://doi.org/10.1017/S0016756800156006

[30] Marsh, O.C. (1878) Principal Characters of American Jurassic Dinosaurs. Part I. American Journal of Science (Series 3), 16, 411-416. https://doi.org/10.2475/ajs.s3-16.95.411

[31] Bonaparte, J.F. and Coria, R.A. (1993) A New and Huge Titanosaur Sauropod from the Rio Limay Formation (Albian-Cenomanian) of Neuquen Province, Argentina. Ameghiniana, 30, 271-282.

[32] Swinton, W.E. (1947) New Discoveries of Titanosaurus indicus Lyd. Annals and Magazine of Natural History (Series 11), 14, 112-123. https://doi.org/10.1080/00222934708654616

[33] Mathur, U.B. and Srivastava, S. (1987) Dinosaur Teeth from Lameta Group (Upper Cretaceous) of Kheda District, Gujurat. Journal of the Geological Society of India, 29, 554-566.

[34] Wilson, J.A. and Upchurch, P. (2003) A Revision of Titanosaurus Lydekker (Dinosauria, Sauropoda), the First Dinosaur Genus with a 'Gondwanan' Distribution. Journal of Systematic Paleontology, 1, 125-160. https://doi.org/10.1017/S1477201903001044

[35] Huene, F.V. and Matley, C.A. (1933) Cretaceous Saurischia and Ornithischia of the Central Provinces of India. Paleontologia Indica, 21, 1-74.

[36] Wilson, J.A. and Mohabey, D.M. (2006) A Titanosauriform (Dinosauria: Sauropoda) Axis from the Lameta Formation (Upper Cretaceous: Maastrichtian) of Nand, Central India. Journal of Vertebrate Paleontology, 26, 471-479. https://doi.org/10.1671/0272-4634(2006)26[471:ATDSAF]2.0.CO;2

[37] Lydekker, R. (1877) Notes of New and Other Vertebrata from Indian Tertiary and Secondary Rocks. Record Geological Survey of India, 10, 30-43.

[38] Malkani, M.S. (2015) Mesozoic Stratigraphy of Pakistan: Special Emphasis on Indus Basin's Revised Stratigraphy. In: Zhang, Y., Wu, S.Z. and Sun, G., Eds., Abstract Volume, 12 th Symposium on "Mesozoic Terrestrial Ecosystems (MTE 12), and 3rd Symposium of International Geoscience Program (IGCP 608) “Cretaceous Ecosystem of Asia and Pacific", Paleontological Museum of Liaoning/Shenyang Normal University, Shenyang, 15-20 August 2015, 255-260.

[39] Malkani, M.S. (2014) Records of Fauna and Flora from Pakistan; Evolution of Indo-Pakistan Peninsula. Abstract Volume of 2 nd Symposium of International Geoscience Program (IGCP 608) "Cretaceous Ecosystem of Asia and Pacific", Tokyo, Japan, 4-6 September 2014, 165-168.

[40] Vredenburg, E.W. (1908) The Cretaceous Orbitoides of India. IBID, 36, 171-213.

[41] Williams, M.D. (1959) Stratigraphy of the Lower Indus Basin, West Pakistan. 5th World Petroleum Congress, New York, 277-394.

[42] Jones, A.G., Manistere, B.E., Oliver, R.L., Willson, G.S. and Scott, H.S. (1961) Reconnaissance Geology of Part of West Pakistan (Colombo Plan Co-Operative Project Conducted and Compiled by Hunting Survey Corporation). Government of Canada, Toronto, $550 \mathrm{p}$.

[43] Malkani, M.S. and Mahmood, Z. (2017) Stratigraphy of Pakistan. Geological Survey of Pakistan, Memoir Volume, 24, 1-134.

[44] Malkani, M.S. and Mahmood, Z. (2016) Revised Stratigraphy of Pakistan. Geologi- 
cal Survey of Pakistan, Record Volume, 127, 1-87.

[45] Prasad, G.V.R. (1989) Vertebrate Fauna from the Infra and Intertrappean Beds of Andhra Pradesh: Age Implications. Journal of the Geological Society of India, 34, 161-173.

[46] Sahni, A. and Bajpai, S. (1991) Eurasiatic Animals in the Upper Cretaceous Nonmarine Biotas of Peninsular India. Cretaceous Research, 12, 177-183. https://doi.org/10.1016/S0195-6671(05)80023-0

[47] Sanz, J.L., Powell, J.E., LeLoeuff, J., Martinez, R. and Pereda-Suberiola, X. (1999) Sauropod Remains from the Upper Cretaceous of Laño (Northcentral Spain), Titanosaur Phylogenetic Relationships. Estudios del Museo de Ciencias Naturales de Nava, 14, 235-255.

[48] Powell, J.E. (1990) Epachthosaurus sciutoi g et sp. nov., un Nuevo dinosaurio titanosaurido del Cretacico de Patagomia. Actas V Congreso Argentino de Paleontologia y Bioestratigrafia, 1, 123-128.

[49] Mannion, P.D., Upchurch, P., Barnes, R.N. and Mateus, O. (2013) Osteology of the Late Jurassic Portuguese Sauropod Dinosaur Lusotitan atalaiensis (Macronaria) and the Evolutionary History of Basal Titanosauriformes. Zoological Journal of the Linnean Society, 168, 98-206. https://doi.org/10.1111/zoj.12029

[50] McIntosh, J.S. (1990) Sauropoda. In: Weishampel, D.B., Dodson, P. and Ósmolska, H., Eds., The Dinosauria, University California Press, Berkeley, CA, 345-401.

[51] Jacobs, L.L., Winkler, D.A., Downs, W.R. and Gomani, E.M. (1993) New material of an Early Cretaceous Titanosaurid Sauropod Dinosaur from Malawi. Palaeontology, 36, 523-534.

[52] Upchurch, P. (1995) The Evolutionary History of Sauropod Dinosaurs. Philosophical Transactions of the Royal Society of London, Series B, 349, 365-390. https://doi.org/10.1098/rstb.1995.0125

[53] Upchurch, P. (1998) The Phylogenetic Relationships of Sauropod Dinosaurs. Zoological Journal of the Linnean Society, 124, 43-103. https://doi.org/10.1111/j.1096-3642.1998.tb00569.x

[54] Salgado, L., Coria, R.A. and Calvo, J.O. (1997) Evolution of Titanosaurids Sauropods. I: Phylogenetic Analysis Based on the Postcranial Evidence. Ameghiniana, 34, 3-32.

[55] Wilson, J.A. (2002) Sauropod Dinosaur Phylogeny: Critique and Cladistic Analysis. Zoological Journal of the Linnean Society, 136, 217-276. https://doi.org/10.1046/j.1096-3642.2002.00029.x

[56] Mannion, P.D. and Calvo, J.O. (2011) Anatomy of the Basal Titanosaur (Dinosauria, Sauropoda) Andesaurus delgadoi from the Mid-Cretaceous (Albian-early Cenomanian) Río Limay Formation, Neuquén Province, Argentina: Implications for Titanosaur Systematics. Zoological Journal of the Linnean Society, 163, 155-181. https://doi.org/10.1111/j.1096-3642.2011.00699.x

[57] Canudo, J.I., Royo-Torres, R. and Cuenca-Bescós, G. (2008) A New Sauropod: Tastavinsaurus sanzi gen. et sp. nov. from the Early Cretaceous (Aptian) of Spain. Journal of Vertebrate Paleontology, 28, 712-731. https://doi.org/10.1671/0272-4634(2008)28[712:ANSTSG]2.0.CO;2

[58] Wang, X., You, H., Meng, Q., Gao, C., Cheng, X. and Liu, J. (2007) Dongbeititan dongi, the First Sauropod Dinosaur from the Lower Cretaceous Jehol Group of Western Liaoning Province, China. Acta Geologica Sinica, 81, 911-916. https://doi.org/10.1111/j.1755-6724.2007.tb01013.x

[59] Dong, Z. (1990) Sauropoda from the Kelameili Region of the Junggar Basin, Xin- 
jiang Autonomous Region. Vertebrata PalAsiatica, 28, 43-58.

[60] Sekiya, T. (2011) Re-Examination of Chuanjiesaurus anaensis (Dinosauria: Sauropoda) from the Middle Jurassic Chuanjie Formation, Lufeng County, Yunnan Province, Southwest China. Memoir of Fukui Prefectural Dinosaur Museum, 10, 1-54.

[61] Bonaparte, J.F., Heinrich, W.-D. and Wild, R. (2000) Review of Janenschia Wild, with the Description of a New Sauropod from the Tendaguru Beds of Tanzania and a Discussion on the Systematic Value of Procoelous Caudal Vertebrae in the Sauropoda. Palaeontographica, Abteilung A, 256, 25-76.

[62] Casanovas, M.L., Santafe, J.V. and Sanz, J.L. (2001) Losillasaurus giganteus, un nuevo sauropodo del transito Jurasico-Cretacico de la cuenca de 'Los Serranos' (Valencia, Espãna). Paleontologia i Evolucio, 32-33, 99-122.

[63] Janensch, W. (1950) Die wirbelsäule von Brachiosaurus brancai. Palaeontographica, 3, 27-93.

[64] D’Emic, M.D. (2012) The Early Evolution of Titanosauriform Sauropod Dinosaurs. Zoological Journal of the Linnean Society, 166, 624-671.

https://doi.org/10.1111/j.1096-3642.2012.00853.x

[65] D'Emic, M.D. (2013) Revision of the Sauropod Dinosaurs of the Early Cretaceous Trinity Group, Southern USA, with the Description of a New Genus. Journal of Systematic Palaeontology, 11, 707-726. https://doi.org/10.1080/14772019.2012.667446

[66] Taylor, M.P., Wedel, M.J. and Cifelli, R.L. (2011) A New Sauropod Dinosaur from the Lower Cretaceous Cedar Mountain Formation, Utah, USA. Acta Palaeontologica Polonica, 56, 75-98. https://doi.org/10.4202/app.2010.0073

[67] You, H.-L., Tang, F. and Luo, Z. (2003) A New Basal Titanosaur (Dinosauria: Sauropoda) from the Early Cretaceous of China. Acta Geologica Sinica, 77, 424-429. https://doi.org/10.1111/j.1755-6724.2003.tb00123.x

[68] Gonzalez Riga, B.J. (2003) A New Titanosaur (Dinosauria, Sauropoda) from the Upper Cretaceous of Mendoza Province, Argentina. Ameghiniana, 40, 155-172.

[69] Royo-Torres, R. (2009) El saurópodo de Peñarroya de Tastavins. Instituto de Estudios Turolenses-Fundación Conjunto Paleontológico de Teruel-Dinópolis, Monografías Turolenses, 6, 1-548.

[70] Curry Rogers, K.A. and Forster, C.A. (2004) The Skull of Rapetosaurus krausei (Sauropoda: Titanosauria) from the Late Cretaceous of Madagascar. Journal of Vertebrate Paleontology, 24,121-144. https://doi.org/10.1671/A1109-10

[71] Yadagiri, P. and Ayyasami, K. (1987) A Carnosaurian Dinosaur from the Kallamedu Formation (Maestrichtian Horizon), Tamil Nadu. Geological Survey of India Special Publications, 1, 523-528.

[72] Malkani, M.S. (2007) Trackways Evidence of Sauropod Dinosaurs Confronted by a Theropod Found from Mid Jur. Samana Suk Limestone of Pakistan. Sindh University Research Journal (Science Series), 39, 1-14.

[73] Nizami, A.R. and Fahim, M. (2015) The Discovery of Ichno-Fossils of the Middle Jurassic Dinosaurs in the Central Salt Range, District Khoshab, Punjab, Sub-Himalayas, Pakistan. Punjab University Journal of Zoology, 30, 37-41.

[74] Malkani, M.S. (2015) Footprints and Trackways of Dinosaurs from Indo-Pakistan Subcontinent-Recent Advances in Discoveries from Pakistan. In: Zhang, Y., Wu, S.Z. and Sun, G., Eds., Abstract Volume, 12 th Symposium on "Mesozoic Terrestrial Ecosystems (MTE 12), and 3rd Symposium of International Geoscience Program 
(IGCP 608) "Cretaceous Ecosystem of Asia and Pacific", Paleontological Museum of Liaoning/Shenyang Normal University, Shenyang, 15-20 August 2015, 186-191.

[75] Hunt, A.P., Lockley, M.G., Lucas, S.G. and Meyer, C.A. (1994) The Global Sauropod Fossil Record. GAIA, 10, 261-279.

[76] Wilson, J.A., Malkani, M.S. and Gingerich, P.D. (2005) A Sauropod Braincase from the Pab Formation (Upper Cretaceous, Maastrichtian) of Balochistan, Pakistan. Gondwana Geological Magazine, Special Volume, 8, 101-109.

[77] Malkani, M.S. (2017) A Review of Pakisaurus titanosaur: Associated Skeletons of Sauropod and Theropod Dinosaurs and Mesoeucrocodiles from Pakistan: Discussion on Titanosaurs of Indo-Pak Subcontinent. In: Cheong, D., Lee, Y. and Kim, D., Eds., Commemoration of the 70 th Anniversary of the Geological Society of Korea, Proceedings and Fieldguide book for the Fifth International Symposium of International Geoscience Programme IGCP Project 608 "Cretaceous Ecosystems and Their Responses to Paleoenvironmental Changes in Asia and the Western Pacific", Jeju Island, Korea, 22-28 October 2017, 116-119.

[78] Malkani, M.S. (2020) Exploration of Latest Theropods, Mesoeucrocodiles and Pterosaurs from Pakistan. (In Process)

[79] Malkani, M.S. (2019) Vitakrisaurus saraiki Theropod from South Asia. Open Journal of Geology, 9, 643-645. https://doi.org/10.4236/ojg.2019.910063

[80] Malkani, M.S. (2019) Induszalim bala Mesoeucrocodile from Pakistan. Open Journal of Geology, 9, 623-626. https://doi.org/10.4236/ojg.2019.910058

[81] Wilson, J.A., Malkani, M.S. and Gingerich, P.D. (2001) New Crocodyliform (Reptilia, Mesoeucrocodylia) form the Upper Cretaceous Pab Formation of Vitakri, Balochistan (Pakistan). Contributions from Museum of Paleontology, University of Michigan, 30, 321-336.

[82] Malkani, M.S. (2010) Updated Stratigraphy and Mineral potential of Sulaiman (Mid. Indus) Basin, Pakistan. Sindh University Research Journal (Science Series), 42, 39-66.

[83] Dubey, V.S. and Narain, K. (1946) A Note on the Occurrence of Pterosauria in India. Current Science, 15, 287-288. https://doi.org/10.1525/as.1946.15.18.01p0090d

[84] Malkani, M.S. and Mahmood, Z. (2017) Mineral Resources of Pakistan: Provinces and Basins Wise. Geological Survey of Pakistan, Memoir Volume, 25, 1-179.

[85] Malkani, M.S. and Mahmood, Z. (2016) Mineral Resources of Pakistan: A Review. Geological Survey of Pakistan, Record Volume, 128, 1-90.

[86] Malkani, M.S. (2011) Stratigraphy, Mineral Potential, Geological History and Paleobiogeography of Balochistan Province, Pakistan. Sindh University Research Journal (Science Series), 43, 269-290.

[87] Malkani, M.S. (2015) Geodiverse and Biodiverse Heritage of Pakistan Demands for Protection as National and Global Geoparks: An Innovation for the Sustainable Development of Pakistan. In: Zhang, Y., Wu, S.Z. and Sun, G., Eds., Abstract Volume, 12th Symposium on "Mesozoic Terrestrial Ecosystems (MTE 12) and 3rd Symposium of International Geoscience Program (IGCP 608) "Cretaceous Ecosystem of Asia and Pacific", Paleontological Museum of Liaoning/Shenyang Normal University, Shenyang, China, 15-20 August 2015, 247-249.

[88] Wilson, J.A., Mohabey, D.M., Lakra, P. and Bhadran, A. (2019) Titanosaur (Dinosauria, Sauropoda) Vertebrae from the Upper Cretaceous Lameta Formation of Western and Central India. Contributions from the Museum of Paleontology, University of Michigan, 33, 1-27. 